\title{
Die Wahl der Ministerpräsidenten in den Bundesländern. Rechtslage und Staatspraxis
}

\author{
Richard Ley
}

\section{Regierungsbildung und ihre Bedeutung für das Parlament}

Die Regierungsbildung in den Bundesländern ${ }^{1}$ kann man - genauso wie die im Bund - in zwei Phasen unterteilen: (1) die Wahl des Ministerpräsidenten ${ }^{2}$ durch das Landesparlament $^{3}$ sowie die anschließende Vereidigung ${ }^{4}$ des neuen Regierungschefs vor dem Landtag 5 und (2) die Berufung der Minister (Regierungsbildung im engeren Sinne) durch den Ministerpräsidenten ${ }^{6}$ mit der anschließenden Vereidigung vor beziehungsweise im Landtag. ${ }^{7}$

Allein in Bremen ist die zweite Phase kein Recht des Ministerpräsidenten, sondern es erfolgt gemäß Art. 107 Abs.2 S.1 LV-HB die Wahl auch der restlichen Senatsmitglieder durch die Bürgerschaft. ${ }^{8}$ In dieser Phase haben die Parlamente in vielen Bundesländern wichtige Mitwirkungs- und Mitbestimmungsrechte. So bedürfen in sieben Ländern (Baden-Württemberg, Bayern, Hamburg, Hessen, Niedersachsen, Rheinland-Pfalz und dem Saarland $)^{9}$ die Landesregierung oder die Minister der parlamentarischen Bestätigung durch

1 Folgende Abkürzungen werden verwendet: Baden-Württemberg - BW; Bayern - BY; Berlin - B; Brandenburg - BBG; Bremen - HB; Hamburg - HH; Hessen - HE; Mecklenburg-Vorpommern - MV; Nordrhein-Westfalen - NRW; Rheinland-Pfalz - RP; Saarland - SL; Sachsen - S; Sachsen-Anhalt - SA; Schleswig-Holstein - SH; Thüringen - TH.

2 Die Bezeichnung Ministerpräsident wird nachfolgend als Synonym auch für die anderweitige Bezeichnung des Landeschefs in Berlin (Regierender Bürgermeister), Bremen (Präsident des Senats) und Hamburg (Erste Bürgermeisterin / Erster Bürgermeister beziehungsweise Präsidentin / Präsident des Senats) verwendet. Des Weiteren wird im Text in der Regel die männliche Formulierung verwendet, obwohl in den Bundesländern Hamburg, Niedersachsen und Schleswig-Holstein sowohl die weibliche als auch die männliche Bezeichnung benutzt werden.

3 Vgl. Art. 46 Abs.1 LV-BW, Art. 44 LV-BY, Art. 56 Abs.1 LV-B, Art. 83 Abs.1 LV-BBG, Art. 107 Abs. 2 S.2 LV-HB, Art. 34 Abs. 1 LV-HH, Art. 101 Abs.1 LV-HE, Art. 42 Abs. 1 LV-MV, Art. 29 Abs. 1 LV-NS, Art. 52 Abs. 1 und 2 LV-NRW, Art. 98 Abs. 2 S.1 LV-RP, Art. 87 Abs.1 S. 1 LV-SL, Art. 60 Abs. 1 LV-S, Art. 65 Abs. 1 und 2 LV-SA, Art. 26 Abs.2 S.1 und Abs.3 LV-SH, Art. 70 Abs.3 LV-TH.

4 Vgl. Art. 48 LV-BW, Art. 56 LV-BY, $\$ 2$ Abs.1 S.2 SenatorenG, Art. 88 LV-BBG, Art. 109 LVHB, Art. 38 LV-HH, Art. 111 LV-HE, Art. 44 LV-MV, Art. 31 LV-NS, Art. 53 LV-NRW, Art. 100 LV-RP, Art. 89 LV-SL, Art. 61 LV-S, Art. 66 LV-SA, Art. 28 Abs.1 LV-SH, Art. 71 LV-TH.

5 Auch die Bezeichnung Landtag wird nachfolgend als Synonym für das Abgeordnetenhaus in Berlin sowie die Bürgerschaften in Bremen und Hamburg verwendet.

6 Art. 46 Abs.2 S.1 LV-BW, Art. 45 LV-BY, Art. 56 Abs.2 S.1 LV-B, Art. 84 LV-BBG, Art. 34 Abs.2 S.1 LV-HH, Art. 101 Abs.2 LV-HE, Art. 43 S.1 LV-MV, Art. 29 Abs.2 LV-NS, Art. 52 Abs.3 S.1 LV-NRW, Art. 98 Abs.2 S.2 LV-RP, Art. 87 Abs.1 S.2 LV-SL, Art. 60 Abs.4 S.1 LV-S, Art. 65 Abs.3 LV-SA, Art. 26 Abs.2 S.2 LV-SH, Art. 70 Abs. 4 S.1 LV-TH.

7 Vgl. Art. 48 LV-BW, Art. 56 LV-BY, $\$ 3$ Abs.1 S.2 SenatorenG, Art. 88 LV-BBG, Art. 109 LVHB, Art. 38 LV-HH, Art. 111 LV-HE, Art. 44 LV-MV, Art. 31 LV-NS, Art. 53 LV-NRW, Art. 100 LV-RP, Art. 89 LV-SL, Art. 61 LV-S, Art. 66 LV-SA, Art. 28 Abs. 2 LV-SH, Art. 71 LV-TH.

8 Eine ähnliche Regelung gab es früher auch in den Stadtstaaten Berlin und Hamburg.

9 Art. 46 Abs. 3 und 4 LV-BW, Art. 45 LV-BY, Art. 34 Abs. 2 S.2 LV-HH, Art. 101 Abs. 4 LV-HE (Notwendigkeit eines Vertrauensbeschlusses) sowie Art. 101 Abs.2 S.2 LV-HE (Information über 
ausdrücklichen Beschluss, oder sie dürfen ihr Geschäfte erst dann übernehmen, wenn der Landtag ihnen durch einen besonderen Beschluss das Vertrauen ausgesprochen hat. Zur Konstituierung der Landesregierung gehört auch noch die Bestellung eines Stellvertreters des Ministerpräsidenten. Dies wird - außer in Bremen - durch den Ministerpräsidenten selbst vorgenommen. In Mecklenburg-Vorpommern und Nordrhein-Westfalen sind die Landtage darüber zu informieren ${ }^{10}$, und in Bayern sowie Rheinland-Pfalz bedürfen diese Bestellungen sogar der Zustimmung der Landtage. ${ }^{11}$

In den Bestimmungen über die Wahl der Ministerpräsidenten ebenso wie in den besonderen Mitwirkungs- und Mitbestimmungsregelungen über die Regierungsbildung im engeren Sinne wird deutlich, dass die Wahl- und Kreationsfunktion des Landtages unter den Hauptaufgaben des Parlaments ${ }^{12}$ von besonderer Bedeutung ist. Diese Aufgabe wird nun auch in einigen neueren beziehungsweise reformierten Landesverfassungen ausdrücklich hervorgehoben. So wird in den Bestimmungen über die Aufgaben des Parlaments in Mecklenburg-Vorpommern, Sachsen-Anhalt, Schleswig-Holstein und Thüringen die Wahl des Regierungschefs ausdrücklich erwähnt. ${ }^{13}$ Niedersachsen und Rheinland-Pfalz führen neben der Wahl der Ministerpräsidenten konsequenterweise auch die Mitwirkung bei der Regierungsbildung an. ${ }^{14}$

Der durch die Verfassungsreform $2000^{15}$ eingefügte Art. 79 Abs. 1 S.2 LV-RP ${ }^{16}$ verdeutlicht den Rang der Wahl- und Mitwirkungsrechte des Parlaments sehr anschaulich. Nach der Erwähnung des Landtags als oberstes Organ der politischen Willensbildung im einleitenden Satz beginnt in Satz 2 - nach der Feststellung, dass der Landtag das Volk vertritt die Aufzählung seiner Aufgaben mit der Wahl des Ministerpräsidenten und der Bestätigung der Landesregierung; erst im Anschluss daran werden die „üblichen“ Hauptaufgaben des Parlaments genannt wie das Gesetzgebungs- und Budgetrecht, die Kontrolle gegenüber der Exekutive sowie die Repräsentationsfunktion. ${ }^{17}$

die Zusammensetzung der Landesregierung), Art. 29 Abs.3 und 4 LV-NS, Art. 98 Abs.2 S.3 LVRP, Art. 87 Abs.1 S.2 LV-SL.

10 Art. 43 S.2 LV-MV, Art. 52 Abs.3 S.2 LV-NRW.

11 Art. 46 LV-BY, Art. 105 Abs.2 S.3 LV-RP.

12 Vgl. Klaus Stern, Das Staatsrecht der Bundesrepublik Deutschland, Band II, München 1980, $\$ 26$ II 2a, S. 47, nennt vier Hauptfunktionen für das Parlament. Edgar Wagner, in: Christoph Grimm / Peter Caesar (Hrsg.), Verfassung für Rheinland-Pfalz, Kommentar, Baden-Baden 2001, Art. 79 Rn. 2, listet auf der Grundlage des Art. 79 Abs.1 S.2 LV-RP sieben Funktionen auf.

13 Art. 20 Abs.1 S.3 LV-MV, Art. 41 Abs.1 S.3 LV-SA, Art. 10 Abs.1 S.3 LV-SH, Art. 48 Abs.2 LV-TH.

14 Art. 7 S.2 LV-NS, Art. 79 Abs.1 S.2 LV-RP.

15 Vgl. dazu Richard Ley, in: ders. / Siegfried Jutzi (Hrsg.), Staats- und Verwaltungsrecht für Rheinland-Pfalz, Baden-Baden 2005, Entstehung und Entwicklung des Landes Rheinland-Pfalz und seiner Verfassung, Rn. 96 ff.

16 Art. 79 Abs.1 LV-RP lautet: Der Landtag ist das vom Volk gewählte oberste Organ der politischen Willensbildung. Er vertritt das Volk, wählt den Ministerpräsidenten und bestätigt die Landesregierung, beschließt die Gesetze und den Landeshaushalt, kontrolliert die vollziehende Gewalt und wirkt an der Willensbildung des Landes mit in der Behandlung öffentlicher Angelegenheiten, in europapolitischen Fragen und nach Maßgabe von Vereinbarungen zwischen Landtag und Landesregierung.

17 Siegfried Jutzi, Verfassungsreform in Rheinland-Pfalz, in: NJW 2000, S. 1295 ff., S. 1296, bezeichnet diese Änderung als „,volkspädagogisch anmutend“. Zur Diskussion vgl. Edgar Wagner, a.a.O. (Fn. 12), Art. 79 Rn. 2. 


\section{Bedeutung der Wahl des Ministerpräsidenten im Verfassungssystem}

In der Wahl des Ministerpräsidenten durch den Landtag als erstem Akt der Regierungsbildung kommt zum Ausdruck, dass die Landesverfassungen dem vom Grundgesetz gewählten Modell des parlamentarischen Regierungssystems folgen. ${ }^{18}$ In der juristischen Kommentarliteratur wird dies besonders hervorgehoben durch Formulierungen wie: „zentrale Regelung des parlamentarischen Regierungssystems“19, „Grundgedanke des parlamentarischen Regierungssystems“20, „wesentlicher Eckpfeiler des parlamentarischen Regierungssystems" 21 oder "Herzstück des parlamentarischen Regierungssystems deutscher Prägung“22. Mit dieser Grundentscheidung haben sich die Landesverfassungen für die parlamentarische und gegen die präsidiale Demokratie entschieden. ${ }^{23}$

Mit der Wahl des Regierungschefs überträgt das Landesparlament die ihm vom Volke verliehene Legitimation und setzt damit die Legitimationskette fort, in die nach den Grundsätzen der repräsentativen Demokratie alle Organe staatlicher Gewalt eingegliedert werden müssen. ${ }^{24}$ In der rheinland-pfälzischen Verfassung wird das durch die Überschrift des 3. Abschnitts besonders deutlich: „Organe des Volkswillens“. Die Untergliederung erfolgt in die zwei Kapitel: „Der Landtag“ und „Die Landesregierung“.

Die Legitimationskette ist aus einem weiteren Grund von großer Bedeutung. Die Ministerpräsidenten sind nicht nur Regierungschef mit der verfassungsrechtlich verankerten Richtlinienkompetenz ${ }^{25}$, sondern sie nehmen zusätzlich eine Reihe von präsidialen Aufgaben wahr ${ }^{26}$, da es in den Bundesländern das Amt des Staatsoberhauptes nicht gibt. Die Ministerpräsidenten sind somit, wie die Regelungen über die Vertretung des Staates „nach außen“27 in

18 Vgl. Klaus-Eckart Gebauer, in: Christoph Grimm / Peter Caesar (Hrsg.), a.a.O. (Fn. 12), Art. 98 Rn. 12.

19 Alfred Katz, in: Paul Feuchte (Hrsg.), Verfassung des Landes Baden-Württemberg. Kommentar, Stuttgart u.a. 1987, Art. 46 Rn. 1.

20 Peter J. Tettinger, in: Wolfgang Löwer / ders. (Hrsg.), Kommentar zur Verfassung des Landes Nordrhein-Westfalen, Stuttgart u.a. 2002, Art. 52 Rn. 1.

21 Martin Nolte, in: Johannes Caspar / Wolfgang Ewer / ders. / Hans-Joachim Waack (Hrsg.), Verfassung des Landes Schleswig-Holstein. Kommentar, Kiel 2006, Art. 26 Rn. 3.

22 Heinzgeorg Neumann, Die Niedersächsische Verfassung. Handkommentar, Stuttgart u.a. 2000, Art. 29 Rn.1.

23 Vgl. Karl Schweiger, in: Hans Nawiasky / ders. / Franz Knöpfle (Hrsg.), Die Verfassung des Freistaates Bayern, München 2006, Art. 44 Rn. 3; Klaus Müller, Verfassung des Freistaats Sachsen. Kommentar, Baden-Baden 1993, S. 334.

24 Vgl. Edgar Wagner, a.a.O. (Fn. 12), Art. 79 Rn. 41.

25 Vgl. Art. 49 Abs.1 S.1 LV-BW, Art. 47 Abs.2 LV-BY, Art. 58 Abs.2 S.1 LV-B, Art. 89 S.1 LV-BBG, Art. 42 Abs.1 S.2 LV-HH, Art. 102 S.1 LV-HE, Art. 46 Abs.1 LV-MV, Art. 37 Abs.1 S.1 LV-NS, Art. 55 Abs.1 LV-NRW, Art. 104 S.1 LV-RP, Art. 91 Abs.1 S.1 LV-SL, Art. 63 Abs.1 LV-S, Art. 68 Abs.1 LV-SA, Art. 29 Abs.1 S.1 LV-SH, Art. 76 Abs.1 S.1 LV-TH. Bremen kennt keine vergleichbare Regelung.

26 Vgl. hinsichtlich der rheinland-pfälzischen Rechtslage die ausführliche Auflistung bei Richard Ley, in: ders. (Hrsg.), Staats- und Verwaltungsrecht für Rheinland-Pfalz, Baden-Baden 1992, Rn. 91.

27 So die Formulierung in Art. 101 Abs.1 S.1 LV-RP. Ähnliche Regelungen: Art. 50 S.1 LV-BW, Art. 47 Abs.3 LV-BY, Art. 58 Abs.1 S.1 LV-B, Art. 91 Abs.1 S.1 LV-BBG, Art. 103 Abs.1 S.1 LV-HE, Art. 47 Abs.1 LV-MV, Art. 35 Abs.1 LV-NS, Art. 95 Abs.1 LV-SL, Art. 65 Abs.1 LV-S, Art. 69 Abs.1 S.1 LV-SA, Art. 30 Abs.1 S.1 LV-SH, Art. 77 Abs.1 S.1 LV-TH. 
den meisten Bundesländern ${ }^{28}$ zeigen, eben auch die obersten Repräsentanten ihres Bundeslandes. ${ }^{29}$

Abschließend sollte noch auf einen weiteren Aspekt hingewiesen werden: Die Landesregierungen bestehen nach den Verfassungen der Bundesländer aus dem Ministerpräsidenten und den Ministern ${ }^{30}$. Die Ministerpräsidenten sind somit Bestandteil der Landesregierung, aber auf Grund ihres Rechtes die Landesminister zu ernennen und zu entlassen sind sie auch „in gewisser Hinsicht ... ihr(e) Schöpfer“"31.

\section{Zeitpunkt und Zeitraum der Wabl am Anfang der Wahlperiode}

Es entspricht sicher den Vorstellungen des Wahlvolkes, dass nach dem Wahltag möglichst schnell die neue Landesregierung gebildet wird. Demgemäß wurde in der derzeitigen und vorangehenden Wahlperiode auch verfahren (vgl. Tabelle 1).

Von den insgesamt 32 Wahlen der Ministerpräsidenten waren die Hälfte bereits in den konstituierenden Sitzungen der Landtage erfolgt, wobei in Hessen, Niedersachsen, Rheinland-Pfalz ${ }^{32}$, Saarland und Thüringen dies für beide hier untersuchten Wahlperioden gilt. Elf Wahlen (34 Prozent) wurden in der zweiten Sitzung des neu gewählten Landtags durchgeführt, und zwar traf dies in Baden-Württemberg, Bremen und Nordrhein-Westfalen für beide Wahlperioden zu. Drei Wahlen fanden erst in der dritten Sitzung und jeweils eine Wahl in der vierten beziehungsweise fünften Sitzung statt.

Die späten Wahltermine sind meist auf langwierige Koalitionsverhandlungen, wie zum Beispiel nach den letzten Wahlen in Mecklenburg-Vorpommern ${ }^{33}$ und Hamburg ${ }^{34}$, wo neue Koalitionen gebildet werden mussten, sowie der Suche nach einem neuen Kandidaten für das Amt des Ministerpräsidenten im Herbst 2008 in Bayern zurückzuführen. ${ }^{35}$

28 In den Hansestädten vertritt der Senat die Stadtstaaten nach außen; vgl. Art. 118 Abs.1 S.2 LVHB und Art. 43 S.1 LV-HH und in Nordrhein-Westfalen vertritt gemäß Art. 57 LV-NRW die Landesregierung das Land nach außen.

29 Vgl. Klaus-Eckart Gebauer, a.a.O. (Fn. 18), Art. 101 Rn. 1.

30 Vgl. Art. 45 Abs.2 S.1 LV-BW, Art. 43 Abs.2 LV-BY, Art. 55 Abs.1 LV-B, Art. 82 LV-BBG, Art. 33 Abs. 1 und 2 LV-HH, Art. 100 LV-HE, Art. 41 Abs. 2 LV-MV, Art. 28 Abs.2 LV-NS, Art. 51 LV-NRW, Art. 98 Abs.1 LV-RP, Art. 86 LV-SL, Art. 59 Abs.1 S.1 LV-S, Art. 64 Abs.1 S.2 LV-SA, Art. 26 Abs.1 S.2 LV-SH, Art. 70 Abs.2 LV-TH; in den Bundesländern Baden-Württemberg, Bayern, Bremen, Saarland und Sachsen können auch Staatssekretäre etc. Mitglied der Landesregierung sein. Abweichend die Regelung in Bremen (Art. 107 Abs.1 S.1 und 2 LV-HB).

31 So Karl Schweiger, a.a.O. (Fn. 23), Art. 44 Rn. 2.

$32 \mathrm{Zu}$ den Wahlen in Rheinland-Pfalz vgl. Richard Ley, Wahlen und Amtszeit der rheinland-pfälzischen Ministerpräsidenten - Eine verfassungsrechtliche und verfassungshistorische Betrachtung zum Verfassungsjubiläum, in: LKRZ 2007, S. 169 - 175. Nach dieser Untersuchung wurden ab der dritten Wahlperiode bis auf eine Ausnahme alle Wahlen in der Konstituierenden Sitzung durchgeführt.

33 Vgl. dazu Nikolaus Werz / Steffen Schoon, Die mecklenburg-vorpommersche Landtagswahl vom 17. September 2006: Ein halber Regierungswechsel und das Ende des Dreiparteiensystems, in: ZParl, 38. Jg. (2007), H. 1, S. 67 - 83, S. 81 ff.

34 Vgl. dazu Patrik Horst, Die Wahlen zur Hamburger Bürgerschaft vom 24. Februar 2008: Wahlsieger Ole von Beust bildet die erste schwarz-grüne Koalition auf Landesebene, in: ZParl, 39. Jg. (2008), H. 3, S. $509-528$, S. 524 ff.

35 Vgl. dazu Rainer-Olaf Schultze I Jan Grasnick, Die bayerische Landtagswahl vom 28. September 2008: Betriebsunfall oder Ende eines Mythos?, in: ZParl, 40. Jg. (2009), H. 1, S. 34 - 55, S. 51 ff. 


\begin{tabular}{|c|c|c|c|c|c|c|c|c|c|c|}
\hline \multirow[b]{2}{*}{ ( } & & \multirow[t]{2}{*}{ 总㸓 } & $\stackrel{i}{\stackrel{+}{+}}$ & $+\frac{m}{\dot{f}}$ & 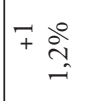 & 0 & $\uparrow \stackrel{0}{\circ}$ & 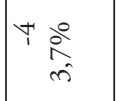 & के & 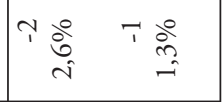 \\
\hline & & & 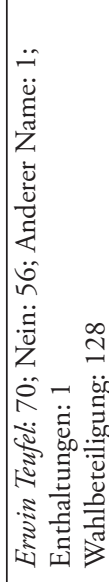 & 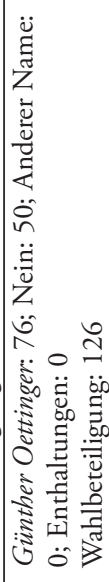 & 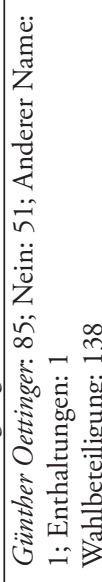 & 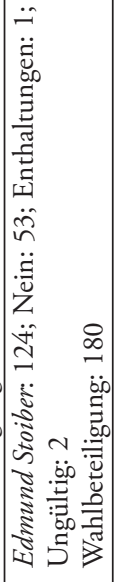 & 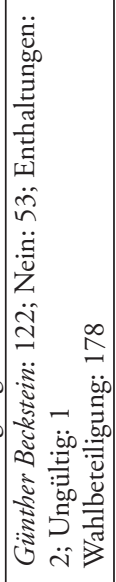 & 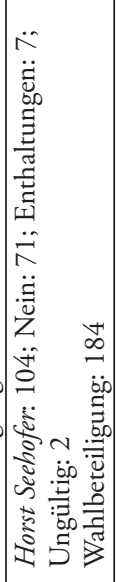 & 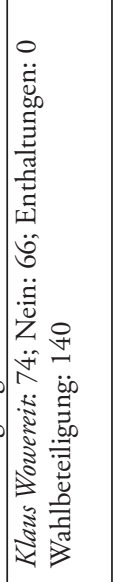 & 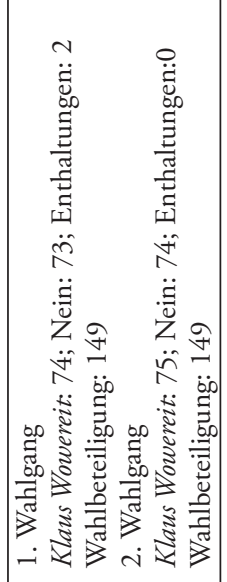 \\
\hline $\mid$ & \multirow{6}{*}{ 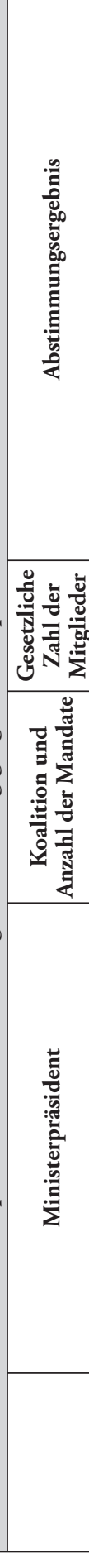 } & 竞莺 & 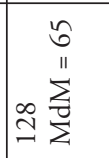 & 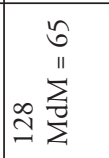 & 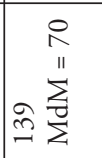 & $\infty \frac{\pi}{2}$ & $\infty \frac{\pi}{\pi}$ & 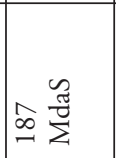 & 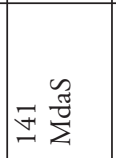 & 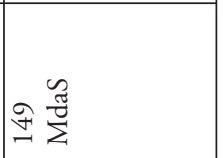 \\
\hline 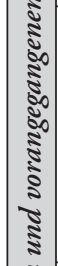 & & & 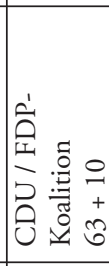 & 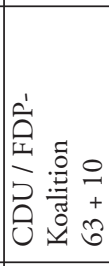 & 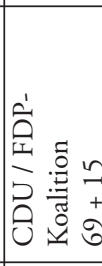 & 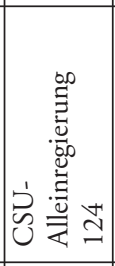 & 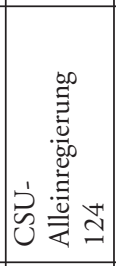 & 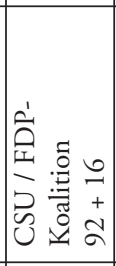 & 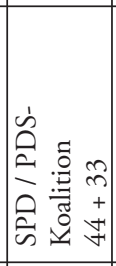 & 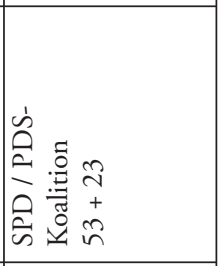 \\
\hline 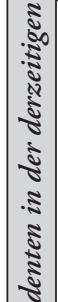 & & 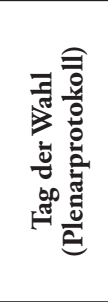 & 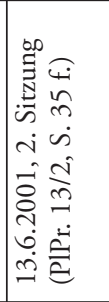 & 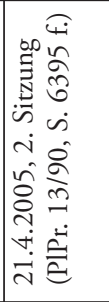 & 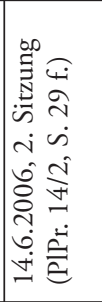 & 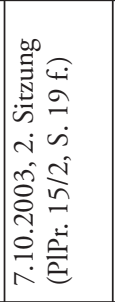 & 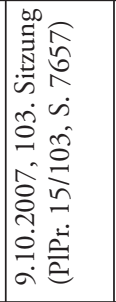 & 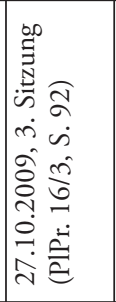 & 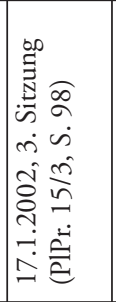 & 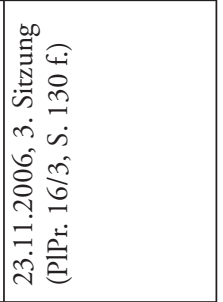 \\
\hline 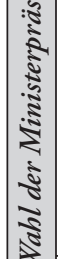 & & 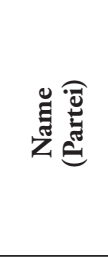 & 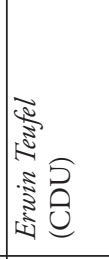 & 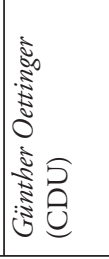 & 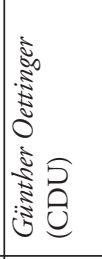 & 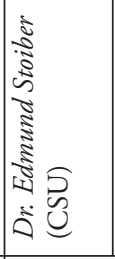 & 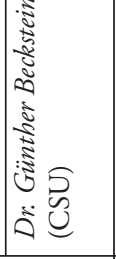 & 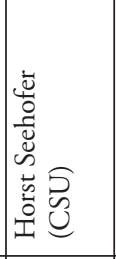 & 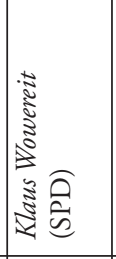 & 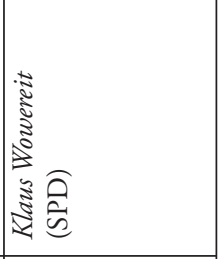 \\
\hline$\ddot{\theta}$ & & 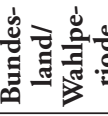 & 㒸 & & 岁 & 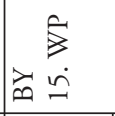 & & $\begin{array}{l}5 \\
0 \\
0\end{array}$ & 象 & $\begin{array}{l}5 \\
0 \\
0 \\
\end{array}$ \\
\hline हैँ & & 㟻艺 & 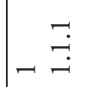 & $\stackrel{\stackrel{\sim}{g}}{=}$ & $\stackrel{\overbrace{}}{ت}$ & $\sim \overrightarrow{\vec{i}}$ & $\stackrel{\text { I }}{\vec{i}}$ & in & $m \vec{n}$ & $\tilde{\omega}$ \\
\hline
\end{tabular}




\begin{tabular}{|c|c|c|c|c|c|c|c|c|c|}
\hline tro & 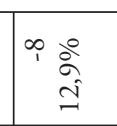 & $\stackrel{\text { i }}{\stackrel{2}{2}}$ & Tे & 个产 & 0 & ते & $7 \stackrel{\circ}{\circ}$ & 0 & \\
\hline 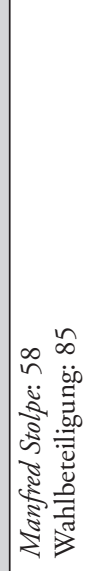 & 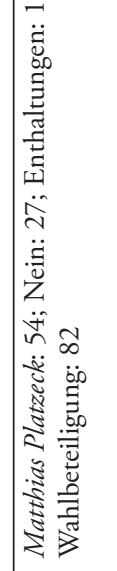 & 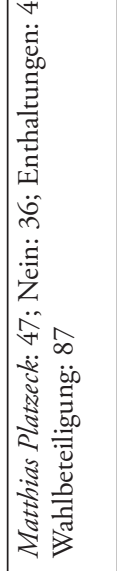 & 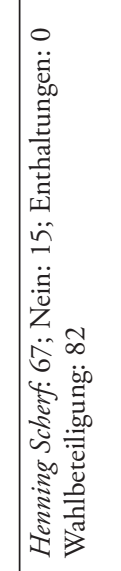 & 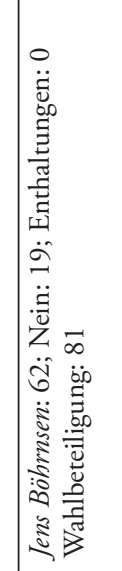 & 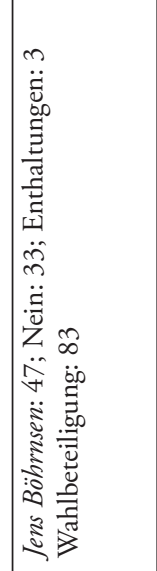 & 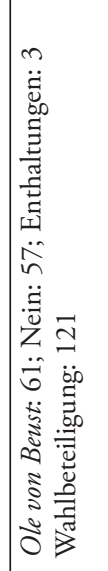 & 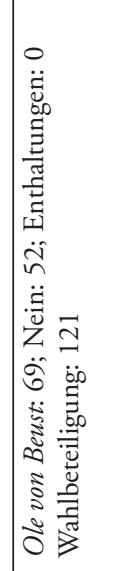 & 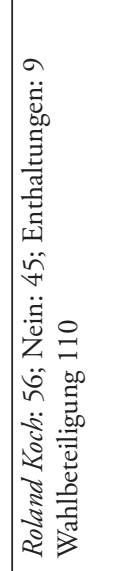 & \\
\hline 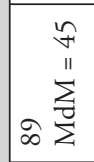 & 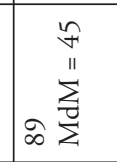 & 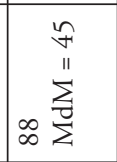 & $\infty \frac{\pi}{v_{n}^{n}}$ & $\infty \frac{\pi}{\tilde{n}}$ & 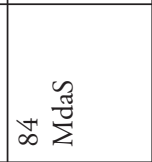 & 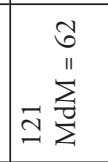 & 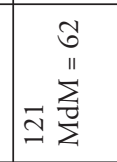 & 垈 & 垔 \\
\hline 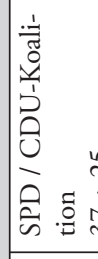 & 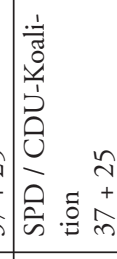 & 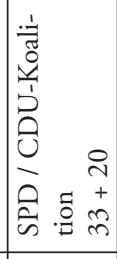 & 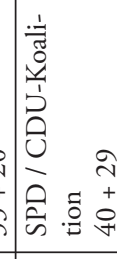 & 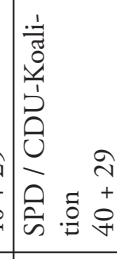 & 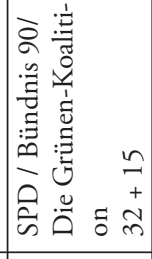 & 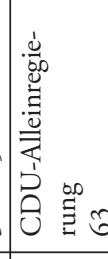 & 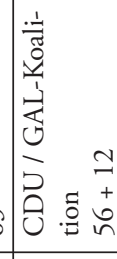 & 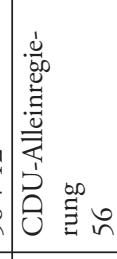 & 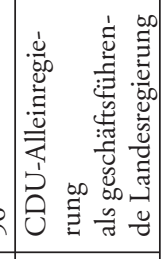 \\
\hline 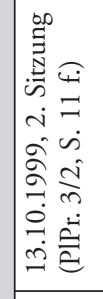 & 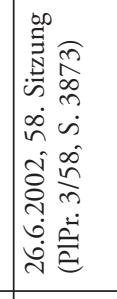 & 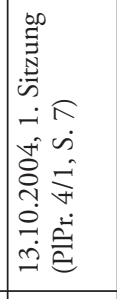 & 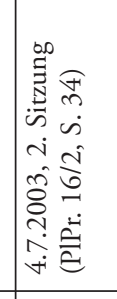 & 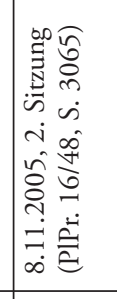 & 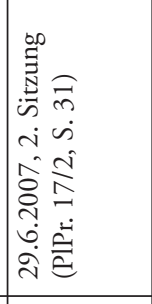 & 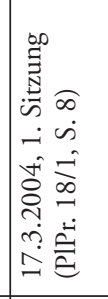 & 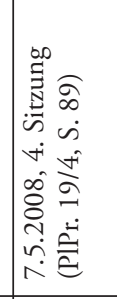 & 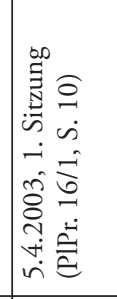 & 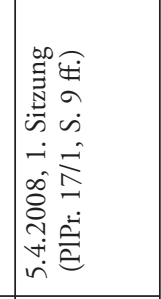 \\
\hline 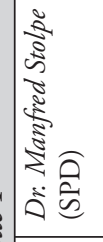 & 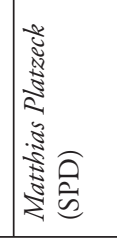 & 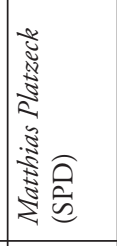 & 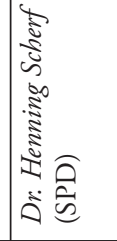 & 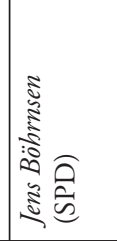 & 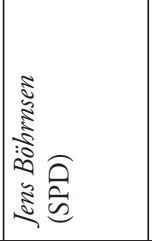 & 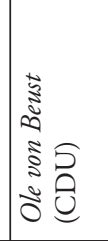 & 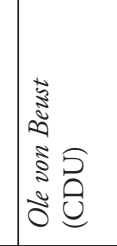 & 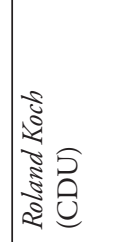 & 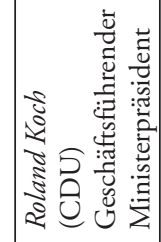 \\
\hline 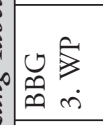 & & 斿 & 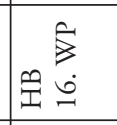 & & $\underline{3}$ & $\begin{array}{l}\hat{s} \\
\Phi \\
\Phi\end{array}$ & $\mid \begin{array}{l}\hat{3} \\
\dot{\Omega}\end{array}$ & 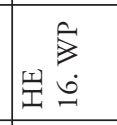 & 告 \\
\hline $\overrightarrow{\overrightarrow{+}}$ & $\vec{F}$ & İ & in $\overrightarrow{\dot{m}}$ & $\frac{7}{3}$ & in & $6 \overrightarrow{0}$ & తి & $\triangle \vec{N}$ & $\stackrel{2}{n}$ \\
\hline
\end{tabular}




\begin{tabular}{|c|c|c|c|c|c|c|c|c|c|c|}
\hline & $\frac{T^{+}}{\gamma^{\circ}}$ & 0 & 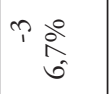 & $\begin{aligned} n & \stackrel{0}{\circ} \\
\Xi & =\end{aligned}$ & 1 & 0 & 0 & 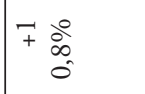 & 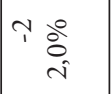 & $\begin{array}{cc}-1 & 0 \\
1 & \infty \\
-\end{array}$ \\
\hline & 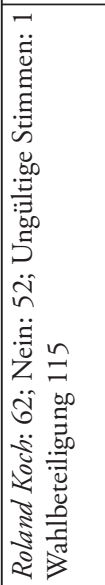 & 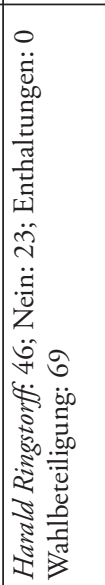 & 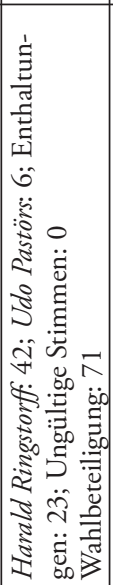 & 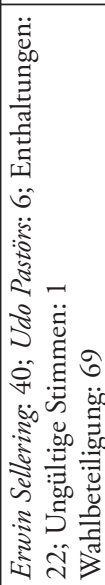 & 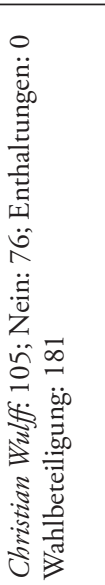 & 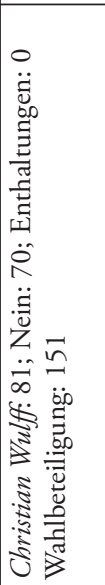 & 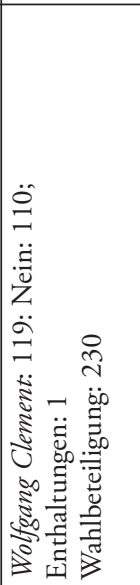 & 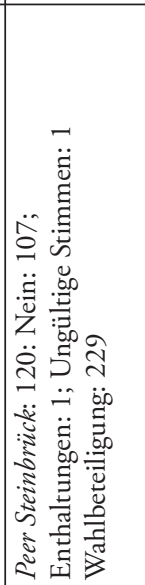 & 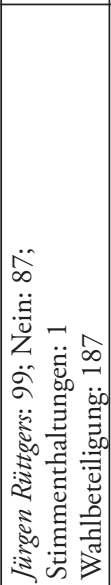 & 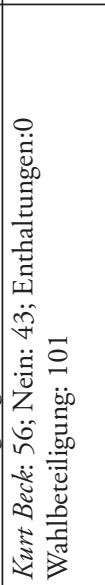 \\
\hline & 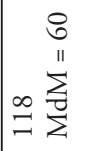 & $\begin{array}{c}\substack{n \\
11 \\
n} \\
\sum \sum\end{array}$ & $\begin{array}{c}\substack{n \\
n \\
\sum} \\
\sum \\
\sum\end{array}$ & 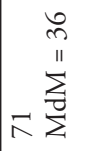 & $\underset{\infty}{\infty}$ & 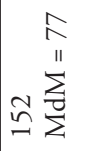 & 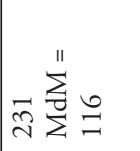 & 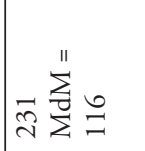 & $\sum_{\infty}^{\infty}$ & 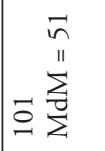 \\
\hline & 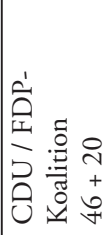 & 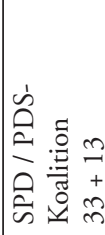 & 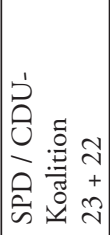 & 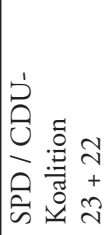 & 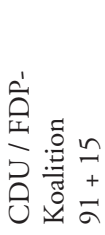 & 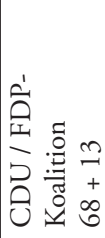 & 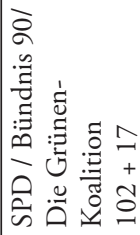 & 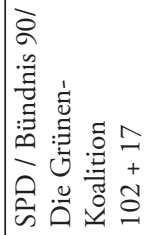 & 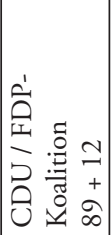 & 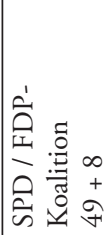 \\
\hline & 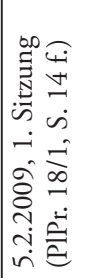 & 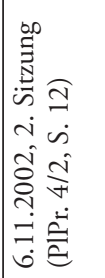 & 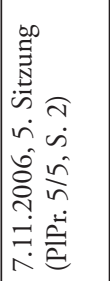 & 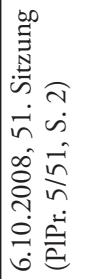 & 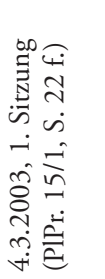 & 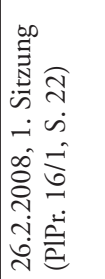 & 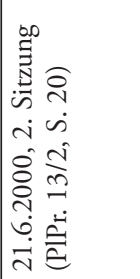 & 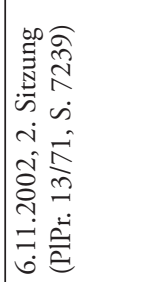 & 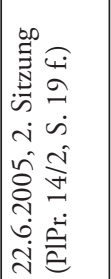 & 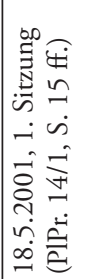 \\
\hline 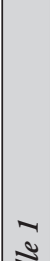 & 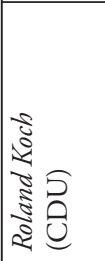 & 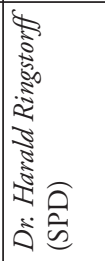 & 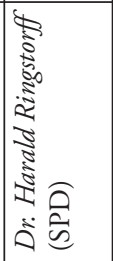 & 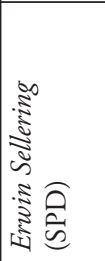 & 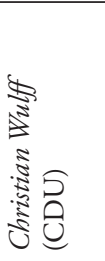 & 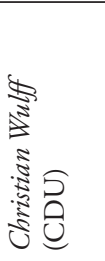 & 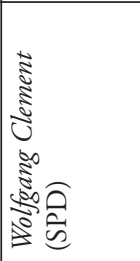 & 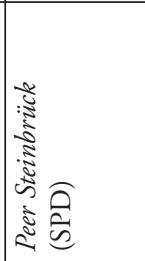 & 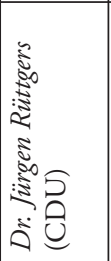 & 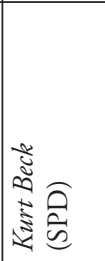 \\
\hline 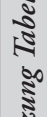 & & $\sum \stackrel{5}{i}$ & $\begin{array}{l}5 \\
\text { in }\end{array}$ & & $\tilde{z}$ & 番 & \multicolumn{2}{|l|}{ 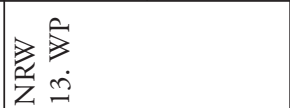 } & Di & $\begin{array}{l}5 \\
\tilde{x} \\
\tilde{y}\end{array}$ \\
\hline 㝴 & & $\infty \vec{\infty}$ & $\underset{\infty}{\infty}$ & 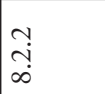 & $a \vec{a}$ & $\stackrel{2}{a}$ & $\stackrel{7}{\circ}$ & $\stackrel{+}{\longrightarrow}$ & $\stackrel{1}{0}$ & $=\rightleftarrows$ \\
\hline
\end{tabular}




\begin{tabular}{|c|c|c|c|c|c|c|c|c|c|c|}
\hline & $+\stackrel{2}{2}$ & 0 & 0 & $\begin{array}{l}1 \\
\text { r }\end{array}$ & $\begin{array}{c}Y \\
\text { Y } \\
\text { ñ } \\
n\end{array}$ & 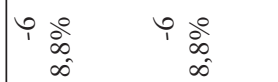 & 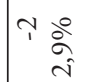 & $\stackrel{m}{+} \dot{b}_{\forall}^{\circ}$ & Y' & 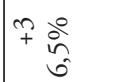 \\
\hline & 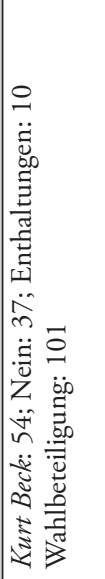 & 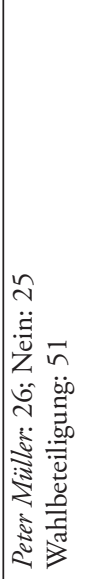 & 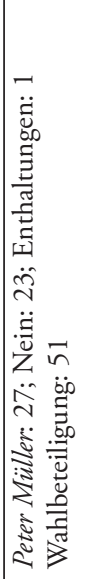 & 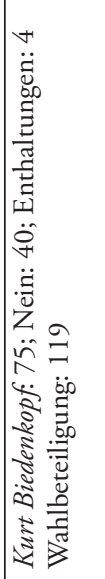 & 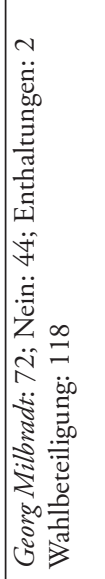 & 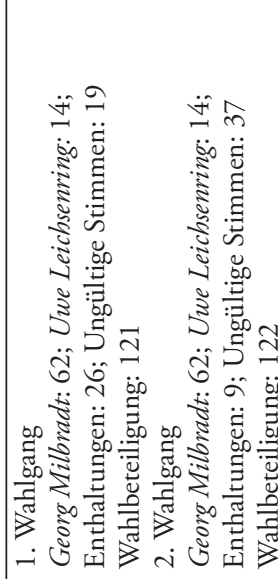 & 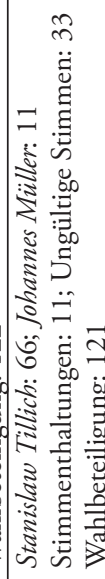 & 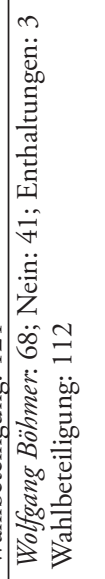 & 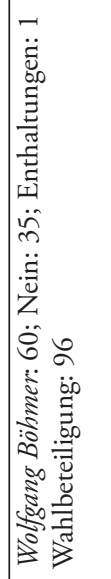 & 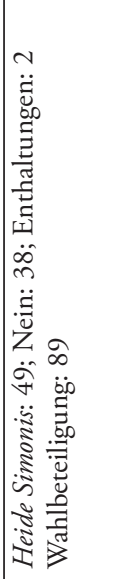 \\
\hline & 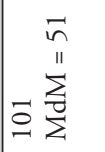 & 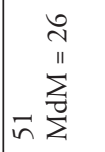 & $\sqrt{\substack{N \\
1 \\
\sum_{n}}}$ & 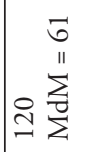 & 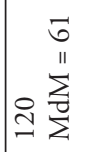 & 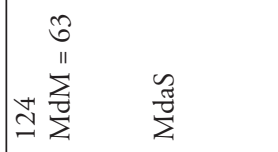 & 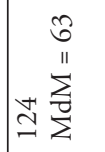 & $\cong \sum_{=}^{\infty} \stackrel{\substack{n \\
\sum}}{n}$ & 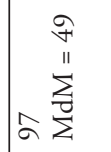 & $\sum_{\infty}^{\substack{n \\
\sum}}$ \\
\hline & 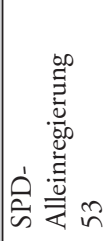 & 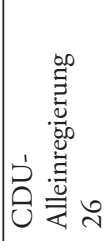 & |c & 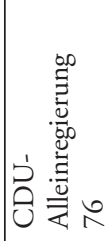 & 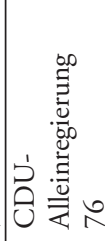 & 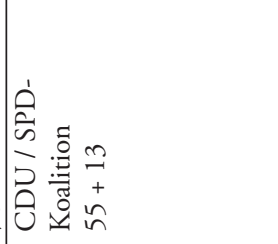 & 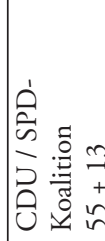 & 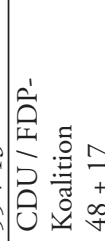 & 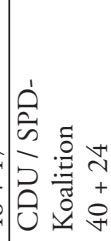 & 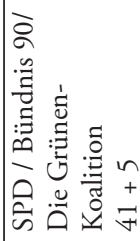 \\
\hline & 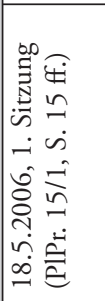 & 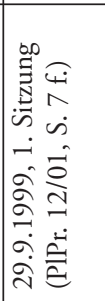 & 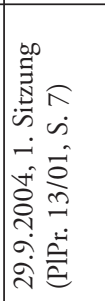 & 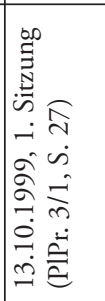 & 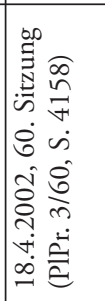 & 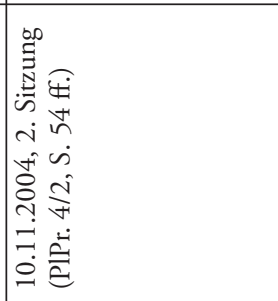 & 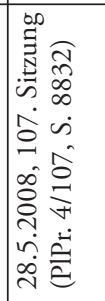 & 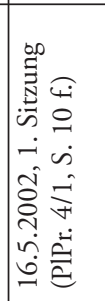 & 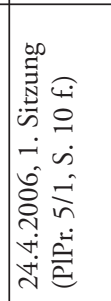 & 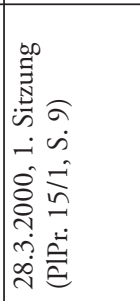 \\
\hline $\begin{array}{l}\longleftarrow \\
\Xi\end{array}$ & 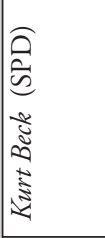 & 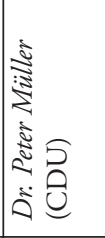 & 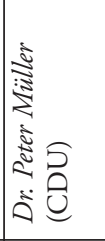 & 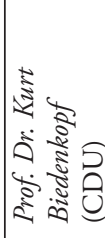 & 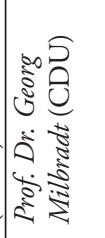 & 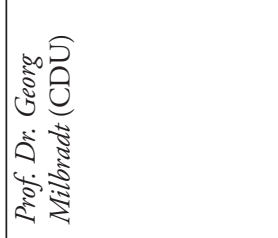 & 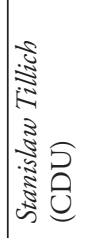 & 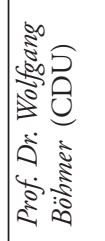 & 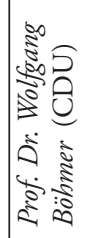 & 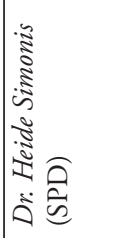 \\
\hline 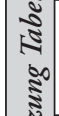 & $\begin{array}{l}5 \\
15 \\
15\end{array}$ & \begin{tabular}{l}
5 \\
$\sqrt[3]{3}$ \\
\multirow{3}{3}{}
\end{tabular} & 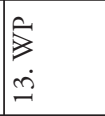 & $\sin$ & & ti & & $\underset{n}{\stackrel{5}{3}}$ & $\begin{array}{l}5 \\
\text { in }\end{array}$ & 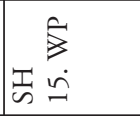 \\
\hline 芯 & $\stackrel{\sim}{=}$ & $\simeq \vec{I}$ & $\stackrel{\text { İ }}{\text { ב }}$ & $\ddot{2}$ & $\stackrel{\sim}{\stackrel{n}{\sim}}$ & $\begin{array}{l}\ddot{\sim} \\
\ddot{n} \\
\ddot{z}\end{array}$ & \begin{tabular}{l}
$\sim$ \\
\cline { 1 - 1 } \\
$\ddot{z}$
\end{tabular} & $\pm \underset{ \pm}{ }$ & $\stackrel{\sim}{\underset{H}{+}}$ & $\simeq \vec{n}$ \\
\hline
\end{tabular}




\begin{tabular}{|c|c|c|c|c|c|c|}
\hline & ने बे & $\begin{array}{l}n \text { o } \\
\text { in } \\
\text { os }\end{array}$ & 0 & $\stackrel{\leftrightarrow}{\stackrel{F}{\rightleftarrows}}$ & 0 & 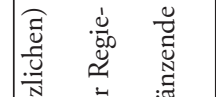 \\
\hline & 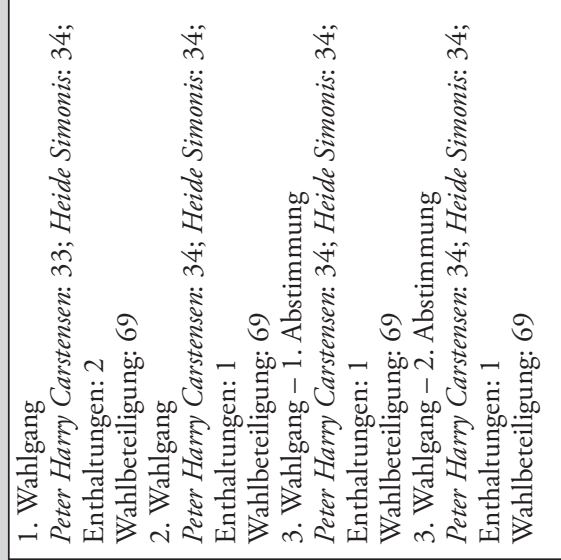 & 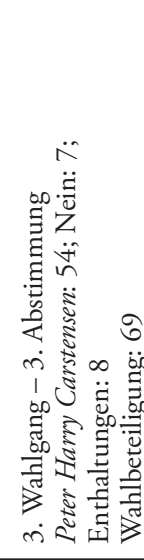 & 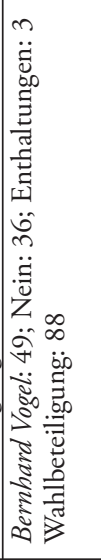 & 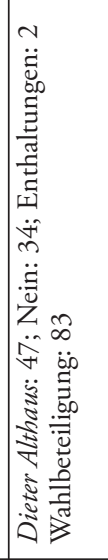 & 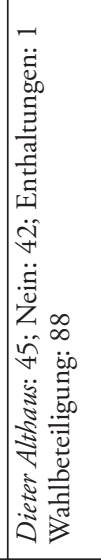 & 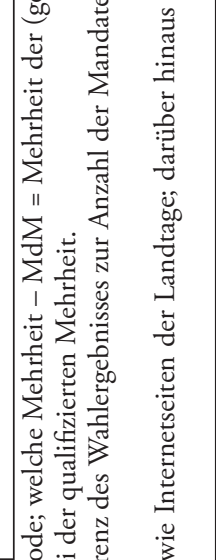 \\
\hline & $8 \sum_{i}^{n}$ & & $\underset{\infty}{\substack{n+1 \\
\infty}}$ & $\sum_{\infty}^{\substack{n \\
\infty}}$ & $\sum_{\infty}^{\substack{n \\
\infty}}$ & 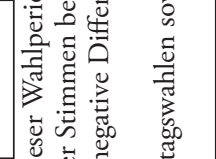 \\
\hline & 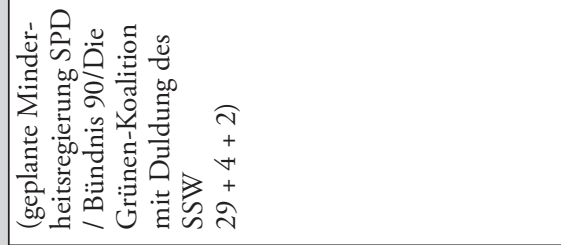 & 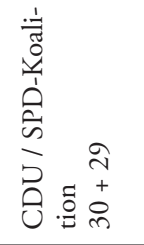 & 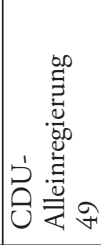 & 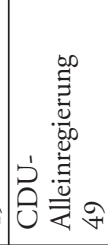 & 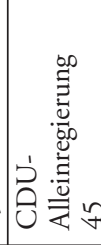 & 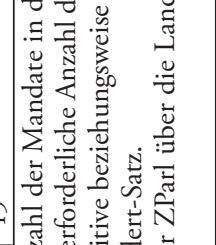 \\
\hline & 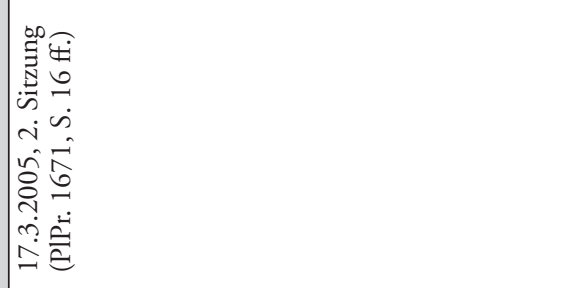 & 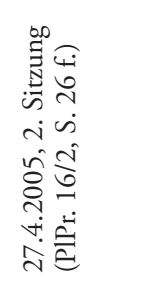 & 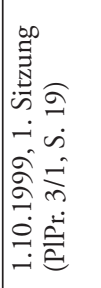 & 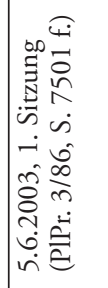 & 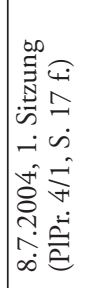 & 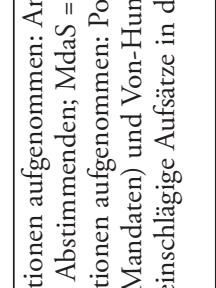 \\
\hline & 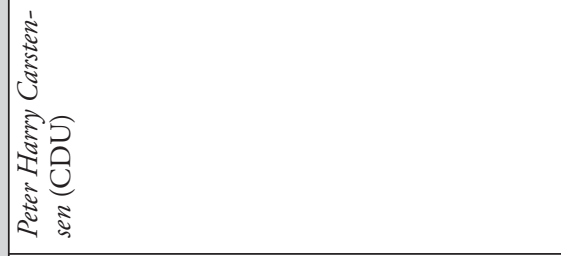 & & 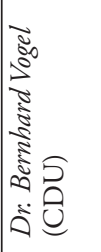 & 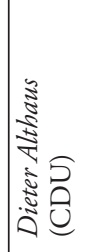 & 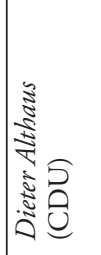 & 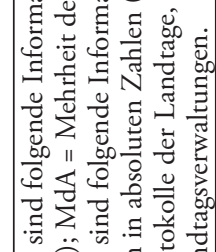 \\
\hline & $\mid \begin{array}{l}5 \\
\dot{3} \\
0\end{array}$ & & 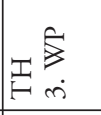 & & i & 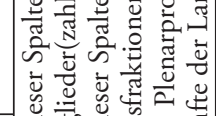 \\
\hline & in & & تُ & 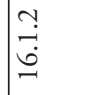 & In & * \\
\hline
\end{tabular}


Die frühzeitigen Wahlen haben aber auch verfassungsrechtliche Gründe. In den meisten Bundesländern gibt es Bestimmungen über das Ende der Amtszeit der Ministerpräsidenten sowie direkte oder indirekte Regelungen über den Zeitpunkt der Wahl zu Anfang der Wahlperiode beziehungsweise den Zeitraum für mögliche Wahlen (vgl. Tabelle 2).

\subsection{Koppelung von Amtszeit und Wahlperiode}

In Baden-Württemberg, Brandenburg, Hamburg, Mecklenburg-Vorpommern, NordrheinWestfalen, Saarland, Sachsen, Sachsen-Anhalt und Thüringen endet die Amtszeit des Ministerpräsidenten mit dem Zusammentritt des neu gewählten Landtages. In diesen zehn Bundesländern ist der Regierungschef verpflichtet, bis zur Amtsübernahme des Nachfolgers die Geschäfte weiterzuführen. Im Prinzip kennt Hessen dieselbe Regelung. Danach muss der Ministerpräsident zurücktreten, sobald der neue Landtag sich konstituiert hat. Auch hier führt der Ministerpräsident die laufenden Geschäfte bis zur Übernahme durch den neuen Amtsinhaber weiter. Vergleichbare Regelungen gibt es in Bayern und Bremen, wo der Ministerpräsident beziehungsweise der Präsident des Senats auf die Dauer einer Wahlperiode gewählt wird.

In all diesen Bundesländern ist somit kraft Verfassung am Anfang der neuen Wahlperiode kein gewählter, sondern nur ein geschäftsführender Regierungschef im Amt, der somit neu besetzt werden muss. Eine Pflicht der Landtage ist schon auf Grund dieser Rechtslage gegeben.

Keine diesbezüglichen Regelungen über die Koppelung vom Amtszeit und Wahlperiode kennen nur Berlin, Rheinland-Pfalz und Sachsen-Anhalt. In Sachsen-Anhalt ist jedoch die Rechtslage eindeutig, da nach Art. 65 Abs.2 S.1 LV-SA innerhalb von 14 Tagen nach dem Zusammentritt des Landtages der erste Wahlgang durchgeführt werden muss.

Die Rechtsfolgen der fehlenden Regelung in Rheinland-Pfalz sind strittig. ${ }^{36}$ Teils wird die Meinung vertreten, dass Art. 98 Abs.2 S.1 LV-RP so auszulegen ist, dass jeder neue Landtag einen neuen Ministerpräsidenten wählen muss. Die wohl herrschende Literaturmeinung ist jedoch der Ansicht, dass der Ministerpräsident solange im Amt ist, bis ein Nachfolger gewählt wurde. Eine Verpflichtung des Landtages bestehe nicht. Man beruft sich unter anderem auch auf eine Entscheidung des Bundesverfassungsgerichtes ${ }^{37}$ hinsichtlich der früheren nahezu gleichlautenden Regelung in Schleswig-Holstein. ${ }^{38}$ Konsequenterweise hat sich in Rheinland-Pfalz eine Staatspraxis entwickelt, nach der am Anfang des Tagesordnungspunktes „Wahl des Ministerpräsidenten“ in der Regel der Landtagspräsident das Schreiben des Ministerpräsidenten verliest, in dem dieser mitteilt, dass er und seine Minister auf Grund der Neuwahl ihren Rücktritt erklären und bis zur Bestätigung der neuen Regierung die Geschäfte weiterführen. ${ }^{39}$

Auch hinsichtlich der Wahl des Regierenden Bürgermeisters in Berlin werden - wie in Rheinland-Pfalz - unterschiedliche Ansichten vertreten. ${ }^{40}$

36 Vgl. dazu ausführlich die verschiedenen Rechtsansichten bei Richard Ley, a.a.O. (Fn. 32), S. 172 ff.

37 Vgl. BVerfGE 27, S. 44 (S. 55f).

38 Vgl. die Nachweise bei Richard Ley, a.a.O. (Fn. 32), S. 172 f.

39 Vgl. ebenda, S. 172.

40 Vgl. Manfred J. Neumann, in: Gero Pfennig / ders. (Hrsg.), Verfassung von Berlin. Kommentar, Berlin / New York 2000, Art. 56 Rn. 2. 


\begin{tabular}{|c|c|c|}
\hline \multicolumn{3}{|c|}{ 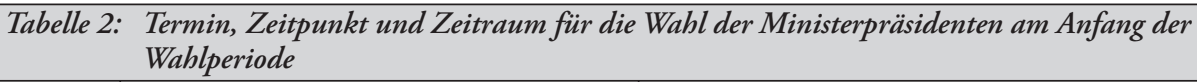 } \\
\hline $\begin{array}{l}\text { Bundes- } \\
\text { land }\end{array}$ & $\begin{array}{l}\text { Termin / Zeitpunkt sowie Zeitraum } \\
\text { für die Wahl }\end{array}$ & $\begin{array}{l}\text { Weitere mögliche Wahlgänge sowie } \\
\text { Rechtsfolge bei erfolgloser Wahl }\end{array}$ \\
\hline BW & $\begin{array}{l}\text { - Das Amt des Ministerpräsidenten endet } \\
\text { mit dem Zusammentritt des neuen Land- } \\
\text { tags (Art. } 55 \text { II LV). } \\
\text { - Regierungsbildung muss innerhalb von } \\
\text { drei Monaten nach dem Zusammentritt } \\
\text { des Landtages erfolgen (Art. } 47 \text { LV). }\end{array}$ & $\begin{array}{l}\text { Weitere Wahlmöglichkeiten innerhalb von } \\
\text { drei Monaten nach Zusammentritt des Land- } \\
\text { tages ansonsten ist der Landtag aufgelöst } \\
\text { (Art. } 47 \mathrm{LV} \text { ). }\end{array}$ \\
\hline BY & $\begin{array}{l}\text { - Wahl spätestens innerhalb einer Woche } \\
\text { nach dem Zusammentritt des neuen Land- } \\
\text { tages. Für die Dauer von fünf Jahren } \\
\text { (= Wahlperiode) (Art. 44 I LV). } \\
\text { - Kommt die Neuwahl innerhalb von vier } \\
\text { Wochen nicht zustande, muss der Land- } \\
\text { tagspräsident den Landtag auflösen } \\
\text { (Art. } 44 \text { V LV). }\end{array}$ & $\begin{array}{l}\text { - Weitere Wahlmöglichkeiten innerhalb des } \\
\text { Zeitraums von vier Wochen nach dem Zusam- } \\
\text { mentritt des Landtages (Art. } 44 \text { V LV). } \\
\text { - Stichwahl, wenn keiner der Bewerber die } \\
\text { erforderliche Mehrheit erreicht } \\
(\$ 45 \text { GOLT). }\end{array}$ \\
\hline B & - & $\begin{array}{l}\text { Kommt beim ersten Wahlgang eine Entschei- } \\
\text { dung nicht zustande, so wird die Wahl wieder- } \\
\text { holt ( } \$ 75 \text { S.2 GO-Abgeordnetenhaus). }\end{array}$ \\
\hline BBG & $\begin{array}{l}\text { - Die Amtszeit des Ministerpräsidenten } \\
\text { endet mit dem Zusammentritt eines neuen } \\
\text { Landtages (Art. 85 I } 1 \text { LV). } \\
\text { - Der Ministerpräsident muss die Geschäfte } \\
\text { bis zum Amtsantritt des Nachfolgers fort- } \\
\text { führen (Art. } 85 \text { II). } \\
\text { - Wahlen innerhalb von drei Monaten } \\
\text { nach Konstituierung des Landtages } \\
\text { (Art. } 83 \text { III LV). } \\
\end{array}$ & $\begin{array}{l}\text { - Erhält im ersten Wahlgang keiner der Vorge- } \\
\text { schlagenen die Mehrheit, findet ein zweiter } \\
\text { Wahlgang statt. Kommt die Wahl auch in die- } \\
\text { sem Wahlgang nicht zustande, so ist gewählt, } \\
\text { wer in einem weiteren Wahlgang die meisten } \\
\text { Stimmen erhält (Art. } 83 \text { II LV). } \\
\text { - Kommt innerhalb der drei Monate keine } \\
\text { Wahl zustande, so gilt der Landtag als aufgelöst } \\
\text { (Art. } 83 \text { III LV). }\end{array}$ \\
\hline HB & $\begin{array}{l}\text { - Die Senatsmitglieder werden für die } \\
\text { Dauer der Wahlperiode der Bürgerschaft } \\
\text { gewählt (Art. } 107 \text { II 1 LV). } \\
\text { - Bis zur Wahl eines Senats durch die neue } \\
\text { Bürgerschaft führt der bisherige Senat die } \\
\text { Geschäfte weiter (Art. 107 III LV). } \\
\end{array}$ & - \\
\hline HH & $\begin{array}{l}\text { - Die Amtszeit endet mit Zusammentritt } \\
\text { einer neuen Bürgerschaft (Art. 35 I LV). } \\
\text { - Weiterführung der Geschäfte durch den } \\
\text { Senat bis zur Wahl eines neuen Ersten } \\
\text { Bürgermeisters (Art. } 37 \text { I 1 LV). }\end{array}$ & - \\
\hline $\mathrm{HE}$ & $\begin{array}{l}\text { Der Ministerpräsident muss zurücktreten, } \\
\text { sobald ein neu gewählter Landtag erstmalig } \\
\text { zusammentritt (Art. 113 II LV). }\end{array}$ & - \\
\hline MV & $\begin{array}{l}\text { - Amt des Ministerpräsidenten endet mit } \\
\text { Zusammentritt eines neuen Landtages } \\
\text { (Art. } 50 \text { I LV). } \\
\text { - Weiterführung des Amtes bis zur Amts- } \\
\text { übernahme des Nachfolgers (Art. } 50 \text { IV } \\
\text { LV). } \\
\text { - Für die Wahlen ist ein Zeitraum von } \\
\text { maximal vier Wochen vorgesehen } \\
\text { (Art. } 42 \text { II } 1 \text { LV). }\end{array}$ & $\begin{array}{l}\text { - Kommt eine Wahl nicht innerhalb von vier } \\
\text { Wochen nach Zusammentritt des neuen Land- } \\
\text { tages zustande so beschließt der Landtag inner- } \\
\text { halb von zwei Wochen seine Auflösung } \\
\text { (Art. } 42 \text { II } 1 \mathrm{LV} \text { ). } \\
\text { - Wird die Beendigung der Wahlperiode durch } \\
\text { den Landtag nicht beschlossen, so findet am } \\
\text { selben Tag eine neue Wahl des Ministerpräsi- } \\
\text { denten statt, bei der derjenige gewählt ist, } \\
\text { wer die meisten Stimmen erhält } \\
\text { (Art. } 42 \text { III } 1+2 \mathrm{LV} \text { ). }\end{array}$ \\
\hline
\end{tabular}




\begin{tabular}{|c|c|c|}
\hline \multicolumn{3}{|c|}{ Fortsetzung Tabelle 2} \\
\hline NS & $\begin{array}{l}\text { - Der Ministerpräsident gilt als zurückge- } \\
\text { treten, sobald ein neu gewählter Landtag } \\
\text { zusammentritt (Art. } 33 \text { II LV). } \\
\text { - Verpflichtung zur Weiterführung bis zur } \\
\text { Übernahme der Geschäfte durch den } \\
\text { Nachfolger (Art. } 33 \text { IV LV). } \\
\text { - Zeitraum für die Regierungsbildung und } \\
\text { Regierungsbestätigung sind } 21 \text { Tage seit } \\
\text { dem Zusammentritt des neu gewählten } \\
\text { Landtags (Art. } 30 \text { I 1 LV). }\end{array}$ & $\begin{array}{l}\text { - Weitere Wahlmöglichkeiten innerhalb der } \\
21 \text { Tage-Frist (Art. } 30 \text { I } 1 \text { LV). } \\
\text { - Kommt die Regierungsbildung und Regie- } \\
\text { rungsbestätigung innerhalb von } 21 \text { Tagen nach } \\
\text { dem Zusammentritt des neu gewählten Land- } \\
\text { tages nicht zustande, so beschließt der Landtag } \\
\text { innerhalb von weiteren } 14 \text { Tagen über seine } \\
\text { Aufösung mit der Mehrheit der Mitglieder } \\
\text { des Landtages (Art. } 30 \text { I LV). } \\
\text { - Ist der Beschluss über die Auflösung nicht er- } \\
\text { folgt, findet unverzüglich eine neue Wahl des } \\
\text { Ministerpräsidenten statt. Gewählt ist, wer die } \\
\text { meisten Stimmen enthält (Art. } 30 \text { II 1+2 LV). }\end{array}$ \\
\hline NRW & $\begin{array}{l}\text { - Das Amt des Ministerpräsidenten endet } \\
\text { mit dem Zusammentritt eines neuen } \\
\text { Landtags (Art. } 62 \text { II LV). } \\
\text { - Bis zur Amtsübernahme des Nachfolgers } \\
\text { muss der Ministerpräsident sein Amt wei- } \\
\text { terführen (Art. } 62 \text { III LV). }\end{array}$ & $\begin{array}{l}\text { - Kommt eine Wahl nach Art. } 52 \text { I LV nicht } \\
\text { zustande, erfolgt innerhalb von } 14 \text { Tagen ein } \\
\text { zweiter gegebenenfalls dritter Wahlgang; } \\
\text { gewählt ist, wer mehr als die Hälfte der abge- } \\
\text { gebenen Stimmen erhält (Art. } 52 \text { II } 1 \text { LV). } \\
\text { - Eventuell Stichwahl zwischen den beiden Kan- } \\
\text { didaten, die in der vorherigen Wahl die meisten } \\
\text { Stimmen erhalten haben (Art. } 52 \text { II } 2 \text { LV). }\end{array}$ \\
\hline $\mathbf{R P}$ & - & - \\
\hline SL & $\begin{array}{l}\text { - Das Amt des Ministerpräsidenten endet } \\
\text { mit dem Zusammentritt eines neuen Land- } \\
\text { tags (Art. } 87 \text { III LV). } \\
\text { - Der Ministerpräsident ist verpflichtet das } \\
\text { Amt bis zum Amtsantritt des Nachfolgers } \\
\text { weiterzuführen (Art. } 87 \text { V LV). } \\
\text { - Wahlen innerhalb von drei Monaten } \\
\text { nach Zusammentritt des neu gewählten } \\
\text { Landtages (Art. 87 IV LV). }\end{array}$ & $\begin{array}{l}\text { Weitere Wahlmöglichkeiten innerhalb der drei } \\
\text { Monate nach Zusammentritt des neu gewähl- } \\
\text { ten Landtags, ansonsten ist der Landtag aufge- } \\
\text { löst (Art. } 87 \text { V LV). }\end{array}$ \\
\hline$S$ & $\begin{array}{l}\text { - Das Amt des Ministerpräsidenten endet } \\
\text { mit Zusammentritt eines neuen Landtages } \\
\text { (Art. } 68 \text { II LV). } \\
\text { - Weiterführungspflicht der Geschäfte bis } \\
\text { zur Amtsübernahme des Nachfolgers } \\
\text { (Art. } 68 \text { III LV). } \\
\text { - Wahlzeitraum von vier Monaten nach } \\
\text { Zusammentritt des neu gewählten Land- } \\
\text { tags (Art. } 60 \text { III LV). }\end{array}$ & $\begin{array}{l}\text { - Kommt eine Wahl mit der Mehrheit der Mit- } \\
\text { glieder nicht zustande, so ist gewählt wer in ei- } \\
\text { nem weiteren Wahlgang die Mehrheit der abge- } \\
\text { gebenen Stimmen erhält (Art. } 60 \text { II LV). } \\
\text { - Wird nicht innerhalb von vier Monaten nach } \\
\text { Zusammentritt des neu gewählten Landtages } \\
\text { gewählt, so ist der Landtag aufgelöst } \\
\text { (Art. } 60 \text { III LV). }\end{array}$ \\
\hline SA & $\begin{array}{l}\text { Erster Wahlgang innerhalb von } 14 \text { Tagen } \\
\text { nach Zusammentritt des Landtages } \\
\text { (Art. } 65 \text { II } 1 \mathrm{LV} \text { ). }\end{array}$ & $\begin{array}{l}\text { - Innerhalb von sieben Tagen ein neuer } \\
\text { (zweiter) Wahlgang; notwendig ist auch hier } \\
\text { die Mehrheit der Mitglieder des Landtages } \\
\text { (Art. } 65 \text { II } 2 \text { LV). } \\
\text { - Bei erfolglosem zweiten Wahlgang muss der } \\
\text { Landtag innerhalb von vierzehn Tagen über die } \\
\text { vorzeitige Beendigung der Wahlperiode be- } \\
\text { schließen (Art. } 65 \text { II } 3 \text { LV). } \\
\text { - Wird die vorzeitige Beendigung der Wahl- } \\
\text { periode nicht mit Mehrheit beschlossen, findet } \\
\text { unverzüglich ein weiterer Wahlgang statt; } \\
\text { gewählt ist der Kandidat der die meisten } \\
\text { Stimmen erhält (Art. } 65 \text { II } 4 \text { + } 5 \text { LV). }\end{array}$ \\
\hline
\end{tabular}




\begin{tabular}{|l|l|l|}
\hline \multicolumn{2}{|l|}{ Fortsetzung Tabelle 2} \\
\hline SH & $\begin{array}{l}\text { Das Amt des Ministerpräsidenten endet } \\
\text { mit dem Zusammentritt eines neuen Land- } \\
\text { tages (Art. 27 I LV). }\end{array}$ & $\begin{array}{l}\text { - Erhält im ersten Wahlgang niemand die } \\
\text { Mehrheit (Art. 26 III LV), so findet ein neuer } \\
\text { Wahlgang statt (Art. 26 IV 1 LV). } \\
\text { - Kommt die Wahl auch im zweiten Wahlgang } \\
\text { nicht zustande, so ist gewählt, wer in einem } \\
\text { weiteren Wahlgang die meisten Stimmen erhält } \\
\text { (Art. 26 IV 2 LV). }\end{array}$ \\
\hline TH & $\begin{array}{ll}\text { - Das Amt des Ministerpräsidenten endet } \\
\text { mit Zusammentritt eines neuen Landtags } \\
\text { (Art. 75 II 1 LV). }\end{array}$ & $\begin{array}{l}\text { - Erhält ein Kandidat im ersten Wahlgang nicht } \\
\text { die erforderliche Mehrheit so findet ein neuer } \\
\text { Wahlgang statt (Art. 70 III 2 LV). } \\
\text { - Kann in diesem zweiten Wahlgang der } \\
\text { Kandidat auch nicht die erforderliche Mehrheit } \\
\text { erhalten so ist der gewählt der in einem weite- } \\
\text { ren Wahlgang die meisten Stimmen erhält } \\
\text { (Art. 70 III 3 LV). }\end{array}$ \\
\hline $\begin{array}{l}\text { Amtsgeschäfte bis zum Amtsantritt eines } \\
\text { Nachfolgers (Art. 75 III LV). }\end{array}$ & \multicolumn{2}{|l}{} \\
\hline \multicolumn{2}{|l|}{ Quelle: Eigene Zusammenstellung. }
\end{tabular}

\subsection{Regelungen zu Zeitpunkt und Zeitraum}

Regelungen über den spätesten Zeitpunkt des ersten Wahlgangs kennen Bayern und Sachsen-Anhalt. Danach ist innerhalb einer Woche beziehungsweise von 14 Tagen nach Zusammentritt des Landtages ein neuer Ministerpräsident zu wählen.

Sieben Bundesländer haben einen Zeitraum festgelegt, innerhalb dessen die Wahlen durchgeführt sein müssen. Im Einzelnen sind folgende Zeiträume nach dem ersten Zusammentritt des neu gewählten Landtages festgelegt: Baden-Württemberg - drei Monate, Bayern - vier Wochen, Brandenburg - drei Monate, Mecklenburg-Vorpommern - vier Wochen, Niedersachsen - 21 Tage, Saarland - drei Monate und Sachsen - vier Monate. Die Regelungen in Nordrhein-Westfalen und Sachsen-Anhalt berechnen den Zeitraum für die Wahlen ausgehend vom ersten Wahlgang. So muss in Nordrhein-Westfalen ein zweiter, gegebenenfalls ein dritter Wahlgang innerhalb von 14 Tagen nach dem erfolglosen ersten durchgeführt werden. In Sachsen-Anhalt ist sieben Tage nach dem ersten Wahlgang ein neuer durchzuführen. Bei erfolgloser Wahl hat der Landtag innerhalb von 14 Tagen über die vorzeitige Beendigung seiner Wahlperiode zu beschließen. Wenn diese nicht beschlossen wird, findet unverzüglich ein weiterer Wahlgang statt, bei dem die einfache Mehrheit ausreicht.

\section{Persönliche Anforderungen an den zu Wählenden}

Die meisten Landesverfassungen stellen keine oder nur vereinzelte spezifische Anforderungen an den Kandidaten für das Ministerpräsidentenamt. Die ausdrücklichen Regelungen betreffen in erster Linie Alter und Wählbarkeit (vgl. Tabelle 3).

Ein bestimmtes Mindestalter fordern die Verfassungen von Bayern und BadenWürttemberg, nämlich die Vollendung des 40. beziehungsweise 35. Lebensjahres. In Nordrhein-Westfalen muss der künftige Ministerpräsident Mitglied des Landtages sein. Diese 
Regelung ist im deutschen Verfassungsrecht einmalig und zum Teil nur aus der Entstehungsgeschichte zu erklären. ${ }^{41}$

Eine ausdrückliche Forderung der Wählbarkeit beziehungsweise der Wahlberechtigung und damit auch der deutschen Staatsangehörigkeit kennen die Verfassungen von BadenWürttemberg, Bayern, Bremen und Hamburg. Jedoch wird zutreffend die Ansicht vertreten, dass sich die Wählbarkeit als positive Voraussetzung aus der Systematik der landesverfassungsrechtlichen Bestimmungen und der Natur der Sache auch für die anderen Landesverfassungen ergebe. ${ }^{42}$ Die Ministerpräsidenten, die bei ihrem Amtsantritt vor dem Landtag den Eid ablegen und außerdem in einem besonderen öffentlich-rechtlichen Amtsverhältnis stehen sowie Staatsgewalt ausüben, müssen denknotwendig die deutsche Staatsangehörigkeit besitzen. ${ }^{43}$

Eine sicher nicht nur historisch überholte Forderung enthält Art. 101 Abs.3 LV-HE. Danach dürfen Angehörige früherer Herrscherhäuser kein Regierungsmitglied und damit auch nicht Ministerpräsident in Hessen sein. ${ }^{44}$

\section{Verfahren}

Die Landesverfassungen kennen im Prinzip nur zwei Verfahrensregeln: Die Wahlen der Ministerpräsidenten müssen „ohne Aussprache“ und „in geheimer Abstimmung“ erfolgen (vgl. Tabelle 3). Die geheime Wahl ist zusammen mit der Anforderung „ohne Aussprache“zumindest in den Bundesländern mit verfassungsgesetzlicher beziehungsweise einfachgesetzlicher Regelung - eine zwingende Ausnahme zum Grundsatz, dass die Landtage öffentlich verhandeln ${ }^{45}$, was in allen Bundesländern verfassungsrechtlich abgesichert ist. ${ }^{46}$ Darüber hinaus gibt es in den Geschäftsordnungen einschlägige Detailregelungen über das genaue Verfahren der Stimmabgabe.

\section{1. „Ohne Aussprache“}

Nach elf Landesverfassungen (Baden-Württemberg, Brandenburg, Hessen, MecklenburgVorpommern, Niedersachsen, Nordrhein-Westfalen, Rheinland-Pfalz, Sachsen, SachsenAnhalt, Schleswig-Holstein und Thüringen) muss die Wahl ohne Aussprache erfolgen.

41 Vgl. Peter J. Tettinger, (Fn. 20), Art. 52 Rn. 23 und 5; Christian Dästner, Die Verfassung des Landes Nordrhein-Westfalen. Kommentar, Stuttgart 2002, Art. 52 Rn. 1, dort sind auch Ausführungen zur Entstehungsgeschichte.

42 Vgl. zum Beispiel Martin Nolte, a.a.O. (Fn. 21), Art. 26 Rn. 12.

43 Vgl. Hubert Weis, Regierungswechsel in den Bundesländern, Berlin 1980, S. 22; Martin Nolte, a.a.O. (Fn. 21), Art. 26 Rn. 12; Rolf Groß, in: Friedrich von Zezschwitz (Hrsg.), Verfassung des Landes Hessen, Baden-Baden 1999, Art. 101 Rn. 6.

44 Vgl. zu dieser problematischen Regelung Karl Reinhard Hinkel, Verfassung des Landes Hessen. Kommentar, Wiesbaden 1999, Art. 101 Anm. 3.

$45 \mathrm{Vgl}$. Alfred Katz, a.a.O. (Fn. 19), Art. 46 Rn. 6.

46 Vgl. Art. 33 LV-BW, Art. 22 LV-BY, Art. 42 Abs.2 LV-B, Art. 64 Abs.2 LB-BBG, Art. 91 LV-HB, Art. 21 LV-HH, Art. 89 LV-HE, Art. 31 LV-MV, Art. 22 LV-NS, Art. 42 LV-NRW, Art. 86 LVRP, Art. 72 LV-SL, Art. 48 LV-S, Art. 50 LV-SA, Art. 15 LV-SH, Art. 69 LV-TH. 


\begin{tabular}{|c|c|c|c|}
\hline \multicolumn{4}{|c|}{$\begin{array}{l}\text { Tabelle 3: Anforderungen an die zu wählende Person sowie formelle Anforderungen an die Wabl } \\
\text { und erforderliche Mehrheit }\end{array}$} \\
\hline & $\begin{array}{l}\text { Anforderungen } \\
\text { an zu wählende } \\
\text { Person }\end{array}$ & $\begin{array}{l}\text { Formelle Anforderungen } \\
\text { an den Wahlvorgang }\end{array}$ & $\begin{array}{l}\text { Erforderliche } \\
\text { Mehrheit* }\end{array}$ \\
\hline BW & $\begin{array}{l}\text { - Gewählt werden } \\
\text { kann, wer zum } \\
\text { Landtag wählbar ist } \\
\text { (Art. } 46 \text { I } 2 \text { LV). } \\
\text { - Vollendung des } \\
\text { 35. Lebensjahres } \\
\text { (Art. 46 I } 2 \text { LV) }\end{array}$ & $\begin{array}{l}\text { - ohne Aussprache (Art. } 46 \text { I } 1 \text { LV) } \\
\text { - in geheimer Abstimmung (Art. 46 I } 1 \text { LV) } \\
\text { - Zur Abgabe der Stimmzettel werden die Abgeord- } \\
\text { neten mit Namen aufgerufen ( } \$ 97 \text { I I } 1 \text { GOLT). } \\
\text { - Der Landtag bestimmt, welche besonderen Vor- } \\
\text { kehrungen zur Gewährleistung der geheimen } \\
\text { Durchführung der Wahl zu treffen sind } \\
\text { ( } \$ 97 \text { a I } 2 \text { GOLT). }\end{array}$ & $\begin{array}{l}\text { Mehrheit der Mit- } \\
\text { glieder des Landta- } \\
\text { ges (Art. } 46 \text { I } 1 \text { LV) }\end{array}$ \\
\hline BY & $\begin{array}{l}\text { - Gewählt werden } \\
\text { kann, wer Wahl- } \\
\text { berechtigter Bayer } \\
\text { ist (Art. } 44 \text { II LV). } \\
\text { - muss das } 40 . \text { Le- } \\
\text { bensjahr vollendet } \\
\text { haben (Art. } 44 \text { II } \\
\text { LV) }\end{array}$ & $\begin{array}{l}\text { - Wahl findet geheim statt ( } \$ 42 \text { I Nr. } 2 \text { GOLT). } \\
\text { - Bereitstellung von Namenskarten und amtlichen } \\
\text { Stimmzetteln ( } \$ 42 \text { I Nr. } 3 \text { GOLT) } \\
\text { - getrennte Urnen für Namenskarten und Stimm- } \\
\text { zettel ( } \$ 42 \text { I Nr. } 4 \text { GOLT) } \\
\text { - Namenskarten und Stimmzettel sind im Beisein } \\
\text { des Stimmberechtigten von einem Schriftführer be- } \\
\text { ziehungsweise Mitarbeiter des Landtagsamts in die } \\
\text { jeweilige Urne zu werfen ( } \$ 42 \text { I Nr. } 5 \text { GOLT). } \\
\text { - Wahl erfolgt durch Kennzeichnung eines Kandi- } \\
\text { daten oder durch Beschriftung des Stimmzettels mit } \\
\text { dem Namen des Kandidaten oder mit einem der } \\
\text { Worte „Ja“, „Nein“, „Enthaltung“ oder mit einer } \\
\text { gleichbedeutenden Formulierung ( } \$ 42 \text { III GOLT). }\end{array}$ & $\begin{array}{l}\text { - Der Landtag be- } \\
\text { schließt mit einfa- } \\
\text { cher Mehrheit der } \\
\text { abgegebenen Stim- } \\
\text { men, sofern die Ver- } \\
\text { fassung kein anderes } \\
\text { Stimmverhältnis } \\
\text { vorschreibt } \\
\text { (Art. } 23 \mathrm{I} \text { LV). } \\
\text { - Gewählt ist der } \\
\text { Kandidat, der mehr } \\
\text { als die Hälfte der ab- } \\
\text { gegeben gültigen } \\
\text { Stimmen erhält. Bei } \\
\text { der Ermittlung der } \\
\text { erforderlichen Mehr- } \\
\text { heit werden Enthal- } \\
\text { tungen und im Fall } \\
\text { der Wahl mit mehre- } \\
\text { ren Kandidaten für } \\
\text { einen Sitz auch } \\
\text { Neinstimmen nicht } \\
\text { berücksichtigt ( } \$ 44 \\
\text { S. } 1+2 \text { GOLT). }\end{array}$ \\
\hline B & - & $\begin{array}{l}\text { - mit verdeckten Stimmzetteln ( } \$ 75 \text { S.1 GO-Ab- } \\
\text { geordnetenhaus) } \\
\text { - Die Stimmzettel dürfen erst vor Betreten der } \\
\text { Wahlkabine (bei Namensaufruf) ausgehändigt wer- } \\
\text { den. Die zur Gewährleistung einer geheimen Wahl } \\
\text { aufzustellenden Wahlkabinen sind bei der Stimm- } \\
\text { abgabe zu benutzen ( } \$ 74 \text { II } 2+3 \text { GO-Abgeordne- } \\
\text { tenhaus). } \\
\text { - Die gekennzeichneten Stimmzettel sind in einem } \\
\text { Umschlag in die dafür vorgesehene Wahlurne zu le- } \\
\text { gen. Dies wird von einem Beisitzer vermerkt ( } \$ 74 \\
\text { II } 4+5 \text { GO-Abgeordnetenhaus). } \\
\text { - Ein Mitglied des Abgeordnetenhauses, das seinen } \\
\text { Stimmzettel außerhalb der Wahlkabine gekenn- } \\
\text { zeichnet oder in den Umschlag gelegt hat, ist zu- } \\
\text { rückzuweisen ( } \$ 74 \text { II } 6 \text { GO-Abgeordnetenhaus). }\end{array}$ & $\begin{array}{l}\text { Mehrheit der abge- } \\
\text { gebenen Stimmen } \\
\text { (Art. } 56 \text { I LV) }\end{array}$ \\
\hline
\end{tabular}




\begin{tabular}{|c|c|c|c|}
\hline \multicolumn{4}{|c|}{ Fortsetzung Tabelle 3} \\
\hline BBG & - & $\begin{array}{l}\text { - ohne Aussprache (Art. } 83 \text { I 1LV) } \\
\text { - in geheimer Abstimmung (Art. } 83 \text { I 1LV) }\end{array}$ & $\begin{array}{l}\text { Mehrheit der Mit- } \\
\text { glieder des Landta- } \\
\text { ges (Art. 83 I 1LV) }\end{array}$ \\
\hline HB & $\begin{array}{l}\text { Gewählt werden } \\
\text { kann, wer in die } \\
\text { Bürgerschaft wähl- } \\
\text { bar ist. Er braucht } \\
\text { weder seine Woh- } \\
\text { nung, noch seinen } \\
\text { Aufenthalt in der } \\
\text { Freien Hansestadt } \\
\text { Bremen gehabt zu } \\
\text { haben (Art. } 107 \mathrm{IV} \\
1+2 \mathrm{LV}) \text {. }\end{array}$ & $\begin{array}{l}\text { - Die Senatsmitglieder werden von der Bürgerschaft } \\
\text { gewählt. Dabei wird zunächst der Präsident des Se- } \\
\text { nats in einem gesonderten Wahlgang gewählt (Art. } \\
107 \text { II } 1+2 \text { LV). } \\
\text { - Die Wahl der Mitglieder des Senats erfolgt in ge- } \\
\text { heimer Abstimmung ( } \$ 58 \text { II } 2 \text { GO-Bürgerschaft). } \\
\text { - Bei geheimen Wahlen geben die Schriftführer die } \\
\text { Stimmzettel aus, sammeln sie ein und stellen das } \\
\text { Ergebnis fest (\$58 III GO-Bürgerschaft). } \\
\text { - Bei geheimer Wahl muss die Abstimmung in } \\
\text { Wahlkabinen erfolgen, wenn dies Mitglieder der } \\
\text { Bürgerschaft in Fraktionsstärke verlangen. Die } \\
\text { Stimmzettel dürfen erst nach Namensaufruf, unmit- } \\
\text { telbar vor Betreten der Wahlkabine ausgehändigt } \\
\text { werden. Die Schriftführer haben Stimmenzettel zu- } \\
\text { rückzuweisen, die unter anderem außerhalb der } \\
\text { Wahlkabine gekennzeichnet wurde (\$58 IV GO- } \\
\text { Bürgerschaft). } \\
\text { - Der Wähler muss mit „Ja“, „Nein“ oder „Enthal- } \\
\text { tung“ stimmen können. Fehlt eine Kennzeichnung, } \\
\text { gilt die Stimme als nicht abgegeben ( } \$ 58 \text { VI 2+3 } \\
\text { GO-Bürgerschaft). }\end{array}$ & $\begin{array}{l}\text { Mehrheit der abge- } \\
\text { gebenen Stimmen } \\
\text { (Art. } 107 \text { II } 1 \mathrm{LV})\end{array}$ \\
\hline HH & $\begin{array}{l}\text { Mitglied des Senats } \\
\text { kann werden, wer } \\
\text { zur Bürgerschaft } \\
\text { wählbar ist. Mit- } \\
\text { glied kann auch } \\
\text { werden, wer bei Ab- } \\
\text { tritt seines Amtes } \\
\text { keine Wohnung in } \\
\text { der Freien und } \\
\text { Hansestadt Ham- } \\
\text { burg innehat; er } \\
\text { muss sie in ange- } \\
\text { messener Zeit dort } \\
\text { nehmen (Art. } 34 \text { III } \\
\text { LV). }\end{array}$ & $\begin{array}{l}\text { - geheime Wahl ( } \$ 2 \text { SenatsG) } \\
\text { - Wahlen erfolgen durch Stimmzettel und geheim } \\
\text { mit Möglichkeit der Wahl in Wahlkabinen nach } \\
\text { Anhörung des Ältestenrates ( } \$ 38 \text { I } 1+2 \text { GO-Bür- } \\
\text { gerschaft). } \\
\text { - Eine Beratung findet außerhalb des Verfahrens } \\
\text { nach Art. } 35 \text { III nicht statt. Die Abgabe allgemeiner } \\
\text { Erklärungen ist zulässig, die Erörterung von Perso- } \\
\text { nalfragen ausgeschlossen ( } \$ 38 \text { V GO-Bürger- } \\
\text { schaft). }\end{array}$ & $\begin{array}{l}\text { Mehrheit der gesetz- } \\
\text { lichen Mitglieder } \\
\text { der Bürgerschaft } \\
\text { (Art. 34 I LV) }\end{array}$ \\
\hline HE & $\begin{array}{l}\text { Angehörige der } \\
\text { Häuser, die bis } \\
1918 \text { in Deutsch- } \\
\text { land oder einem an- } \\
\text { deren Land regiert } \\
\text { haben oder in ei- } \\
\text { nem Land regieren, } \\
\text { können nicht Mit- } \\
\text { glied der Landesre- } \\
\text { gierung sein (Art. } \\
101 \text { III LV). }\end{array}$ & $\begin{array}{l}\text { - ohne Aussprache (Art. } 101 \text { I } 1 \text { LV) } \\
\text { - in geheimer Wahl (Art. } 101 \text { I } 2 \text { LV i.V.m. } \$ 7 \\
\text { GOLT) }\end{array}$ & $\begin{array}{l}\text { Mehr als der Hälfte } \\
\text { der gesetzlichen } \\
\text { Zahl der Mitglieder } \\
\text { des Landtages (Art. } \\
\text { 101 I } 1 \text { LV) }\end{array}$ \\
\hline
\end{tabular}




\begin{tabular}{|c|c|c|c|}
\hline \multicolumn{4}{|c|}{ Fortsetzung Tabelle 3} \\
\hline MV & - & $\begin{array}{l}\text { - ohne Aussprache (Art } 42 \text { I LV) } \\
\text { - in geheimer Abstimmung (Art } 42 \text { I LV) }\end{array}$ & $\begin{array}{l}\text { Mehrheit der Mit- } \\
\text { glieder des Landta- } \\
\text { ges (Art. } 42 \mathrm{I} \mathrm{LV} \text { ) }\end{array}$ \\
\hline NS & - & $\begin{array}{l}\text { - ohne Aussprache (Art. 29 I LV) } \\
\text { - in geheimer Abstimmung (Art. 29 I LV) }\end{array}$ & $\begin{array}{l}\text { Mehrheit der Mit- } \\
\text { glieder des Landta- } \\
\text { ges (Art. 29 I LV) }\end{array}$ \\
\hline NRW & $\begin{array}{l}\text { Der Landtag wählt } \\
\text { aus seiner Mitte den } \\
\text { Ministerpräsidenten } \\
\text { (Art. 52 I LV). } \\
\end{array}$ & $\begin{array}{l}\text { - ohne Aussprache (Art. } 52 \text { I LV) } \\
\text { - in geheime Wahl (Art. } 52 \text { I LV) }\end{array}$ & $\begin{array}{l}\text { Mehr als die Hälfte } \\
\text { der gesetzlichen } \\
\text { Zahl der Mitglieder } \\
\text { (Art. } 52 \text { I LV) }\end{array}$ \\
\hline RP & - & $\begin{array}{l}\text { - ohne Aussprache (Art. } 98 \text { II1 LV) } \\
\text { - geheim ( } \$ 49 \text { I } 2 \text { GOLT) }\end{array}$ & $\begin{array}{l}\text { Mehrheit der gesetz- } \\
\text { lichen Mitglieder } \\
\text { (Art. } 98 \text { II1 LV) }\end{array}$ \\
\hline SL & - & $\begin{array}{l}\text { - Wahlen können durch Handaufheben erfolgen, } \\
\text { wenn kein Abgeordneter widerspricht. Zur Abgabe } \\
\text { der Stimmzettel werden die Abgeordneten mit Na- } \\
\text { men aufgerufen ( } \$ 67 \text { I Gesetz über den Landtag } \\
\text { des Saarlandes). } \\
\text { - Bei schriftlicher Wahl erläutert der Präsident vor- } \\
\text { her den Stimmzettel und das Verfahren ( } \$ 53 \\
\text { GOLT). }\end{array}$ & $\begin{array}{l}\text { Mehrheit der gesetz- } \\
\text { lichen Mitglieder- } \\
\text { zahl des Landtages } \\
\text { (Art. } 87 \text { I } 1 \text { LV) }\end{array}$ \\
\hline$S$ & - & $\begin{array}{l}\text { - ohne Aussprache (Art. } 60 \text { I LV) } \\
\text { - in geheimer Abstimmung (Art. } 60 \text { I LV) }\end{array}$ & $\begin{array}{l}\text { Mehrheit der Mit- } \\
\text { glieder des Landta- } \\
\text { ges (Art. } 60 \text { I LV) }\end{array}$ \\
\hline SA & - & $\begin{array}{l}\text { - ohne Aussprache (Art. } 65 \text { I LV) } \\
\text { - in geheimer Abstimmung (Art. } 65 \text { I LV) }\end{array}$ & $\begin{array}{l}\text { Mehrheit der Mit- } \\
\text { glieder des Landta- } \\
\text { ges (Art. } 65 \text { II } 1 \text { LV) }\end{array}$ \\
\hline SH & - & $\begin{array}{l}\text { - ohne Aussprache (Art. } 26 \text { II } 1 \text { LV) } \\
\text { - geheime Abstimmung durch Abgabe von Stimm- } \\
\text { zetteln ( } \$ 63 \text { III } 1+2 \text { GOLT) }\end{array}$ & $\begin{array}{l}\text { Stimmen der Mehr- } \\
\text { heit der Mitglieder } \\
\text { des Landtages (Art. } \\
26 \text { III LV) }\end{array}$ \\
\hline TH & - & $\begin{array}{l}\text { - ohne Aussprache (Art. } 70 \text { III } 1 \text { LV) } \\
\text { - in geheimer Abstimmung (Art. } 70 \text { III } 1 \text { LV) } \\
\text { - Zur Abgabe der Stimmzettel werden die Mitglie- } \\
\text { der mit Namen aufgerufen ( } \$ 46 \text { I } 1 \text { GOLT). } \\
\text { - Der Landtag bestimmt, welche besonderen Vor- } \\
\text { kehrungen zur Gewährleistung der geheimen } \\
\text { Durchführung der Wahl zu treffen sind ( } \$ 46 \text { I } 3 \\
\text { GOLT). }\end{array}$ & $\begin{array}{l}\text { Mehrheit der Mit- } \\
\text { glieder des Landta- } \\
\text { ges (Art. } 70 \text { III } 1 \\
\text { LV) }\end{array}$ \\
\hline \multicolumn{4}{|c|}{$\begin{array}{l}\text { * Die Angaben beziehen sich in jedem Fall auf den ersten Wahlgang. Sind nach erfolglosem ersten } \\
\text { Wahlgang weitere Wahlgänge vorzunehmen, so können andere Mehrheiten gefordert sein. Vgl. dazu } \\
\text { in Tabelle } 2 \text { Spalte } 3 \text {. }\end{array}$} \\
\hline
\end{tabular}


Hamburg hat eine entsprechende Regelung in die Geschäftsordnung aufgenommen. Diese Forderung bedeutet, dass auch - nach wohl herrschender Literaturmeinung ${ }^{47}$ - für den Fall, dass zwei ${ }^{48}$ oder mehr ${ }^{49}$ Kandidaten zur Wahl stehen, keine Personaldebatte stattfindet. Die Plenarprotokolle vermelden in diesem Zusammenhang nur die Antragstellung, meist vorgetragen durch den jeweiligen Fraktionsvorsitzenden, oder es wird auf die entsprechenden bereits eingereichten Anträge verwiesen, die als Parlamentsdrucksachen verteilt wurden. ${ }^{50}$ Eine Antragstellung ist erforderlich, da anders als im Bund in den Ländern wegen des Fehlens eines eigenständigen Staatsoberhauptes kein anderes außenstehendes Organ die Initiative für die Wahl übernehmen kann.

„Ohne Aussprache“ bedeutet aber nicht nur, dass keine Personaldebatte erlaubt ist, sondern auch, dass keine Diskussion über die zu erwartende Regierungspolitik stattfindet. ${ }^{51}$ Jedoch ist selbstverständlich eine Geschäftsordnungsdebatte über den Ablauf oder die Gestaltung des Stimmzettels von diesem Verbot nicht betroffen. ${ }^{52}$

Mit dieser Regelung soll eine Einflussnahme auf das Verhalten der Abgeordneten und damit auch auf den Ausgang der Wahl nicht ausgeschlossen, sondern vielmehr das Ansehen der Kandidaten, insbesondere des späteren Ministerpräsidenten, geschützt werden. ${ }^{53}$ Klaus Braun sieht darin jedoch eine „fragwürdige“ Regelung, die in einem „gewissen Widerspruch zum verfassungsrechtlichen Grundsatz des offenen Prozesses der demokratischen Willensbildung" 54 stehe. Für Rainer Litten ist dies aber eine sinnvolle Regelung. Er führt an, dass nach einer Personal- und Politikdebatte durch die öffentliche Diskussion eventuell Druck auf die Abgeordneten in den eigenen Reihen ausgeübt werden könnte, was eine spätere Wahl gefährdet. ${ }^{55}$

Ein Verstoß gegen diese Formvorschrift, also das Stattfinden einer kurzen Personaldebatte, hätte nicht zur Folge, dass die anschließende Wahl ungültig wäre. ${ }^{56}$

47 Vgl. Alfred Katz, a.a.O. (Fn. 19), Art. 46 Rn. 6; Klaus-Eckart Gebauer, a.a.O. (Fn. 18), Art. 98 Rn. 15 mit weiteren Nachweisen hinsichtlich abweichender Ansichten bezüglich der bundesrechtlichen Regelung.

48 In der derzeitigen Wahlperiode fanden entsprechende Wahlen in Mecklenburg-Vorpommern (PIPr. 5/51 vom 6. Oktober 2008, S. 2) und in Sachsen (PIPr. 4/107 vom 28. Mai 2008, S. 8829 - 8831) statt. Vgl. bezüglich früherer Wahlperioden für Rheinland-Pfalz die Wahlen in der 5. Wahlperiode (PIPr. 5/1 vom 18. Mai 1963, S. 8), 7. Wahlperiode (PIPr. 7/1 vom 18. Mai 1971, S. 10 f.), 8. Wahlperiode (PIPr. 8/1 vom 20. Mai 1975, S. 10) und 9. Wahlperiode (PIPr. 9/1 vom 18. Mai 1979, S. $11 \mathrm{ff}$.$) .$

49 Für Rheinland-Pfalz in der 11. Wahlperiode (PIPr. 11/3 vom 23. Juni 1987, S. 82 - 84).

50 Vgl. dazu zum Beispiel Mecklenburg-Vorpommern (Drs. 5/1834 und 5/1851) sowie Sachsen (Drs. 4/12350 und 4/12367).

51 Vgl. Alfred Katz, a.a.O. (Fn. 19), Art. 46 Rn. 6; Peter J. Tettinger, a.a.O. (Fn. 20), Art. 52 Rn. 22.

52 Vgl. Heinzgeorg Neumann, a.a.O. (Fn. 22), Art. 29 Rn. 6.

53 Vgl. Hubert Weis, a.a.O. (Fn. 43), S. 26; Alfred Katz, a.a.O. (Fn. 19), Art. 46 Rn. 6; Klaus Braun, Kommentar zur Verfassung des Landes Baden-Württemberg, Stuttgart 1984, Art. 46 Rn. 14; Rolf Groß, a.a.O. (Fn. 43), Art. 101 Rn. 3 mit weiteren Nachweisen; Rainer Litten, in: ders. / Maximillian Wallerath (Hrsg.), Verfassung des Landes Mecklenburg-Vorpommern, Baden-Baden 2007, Art. 42 Rn. 3.

54 So Klaus Braun, a.a.O. (Fn. 53), Art. 46 Rn. 14.

55 Vgl. Rainer Litten, a.a.O. (Fn. 53), Art. 42 Rn. 3.

56 Vgl. Alfred Katz, a.a.O. (Fn. 19), Art. 46 Rn. 6 mit weiteren Nachweisen; Rolf Groß, a.a.O. (Fn. 43), Art. 101 Rn. 4 mit weiteren Nachweisen; Heinzgeorg Neumann, a.a.O. (Fn. 22), Art. 29 Rn. 5; Klaus-Eckart Gebauer, a.a.O. (Fn. 18), Art. 98 Rn. 15; Joachim Linck, in: ders. / Siegfried Jutzi 
In den vier Bundesländern, in denen eine Personaldiskussion nicht ausgeschlossen ist, haben sich anscheinend über die Jahre unterschiedliche Rituale herausgebildet. So fanden die beiden letzten Wahlen im Saarland ohne Debatte statt. ${ }^{57}$ Am ausführlichsten waren die Debatten in den beiden letzten Wahlperioden in Berlin. Dort haben nicht nur die Oppositionsfraktionen (CDU, FDP und Grüne) das Wort ergriffen, sondern auch Vertreter der Regierungskoalitionen (SPD und PDS beziehungsweise Die Linken). ${ }^{58}$ Nicht ganz so ausführlich, aber von allen Fraktionen geführt, waren die Debatten in Bremen. ${ }^{59}$ In Bayern haben sich nur bei der Wahl von Horst Seehofer im Oktober 2008 alle Fraktionen an der ausführlichen Diskussion beteiligt. ${ }^{60}$ Durch den „erzwungenen“ Rücktritt des CSU-Kandidaten Günther Beckstein nach der verlorenen Wahl gab es größeren Diskussionsbedarf, und die nun drei Oppositionsfraktionen (SPD, FW, Grüne) wollten sich dieses Forum nicht entgehen lassen. Ansonsten ergriffen nach dem Personalvorschlag durch den Fraktionssprecher der CSU nur die Oppositionsfraktionen das Wort. ${ }^{61}$

\section{2. „In geheimer Abstimmung“}

In allen Bundesländern außer dem Saarland ist eine geheime Abstimmung bei der Wahl des Ministerpräsidenten vorgeschrieben, jedoch ist der Standort der Regelung unterschiedlich (vgl. Tabelle 3). In neun Bundesländern (Baden-Württemberg, Brandenburg, Hessen, Mecklenburg-Vorpommern, Niedersachsen, Nordrhein-Westfalen, Sachsen, Sachsen-Anhalt und Thüringen) steht diese Anforderung in den Landesverfassungen; in Hamburg fordert $\$ 2$ Senatsgesetz, dass die Wahl des Ersten Bürgermeisters in geheimer Wahl erfolgen muss, und in fünf Bundesländern (Bayern, Berlin, Bremen, Rheinland-Pfalz ${ }^{62}$ und Schleswig-Holstein) ist die geheime Wahl - wie im Falle des Bundeskanzlers ${ }^{63}$ - nur durch die entsprechende Geschäftsordnung abgesichert. Nach $\$ 67$ Abs.1 des Gesetzes über den Landtag des Saarlandes können Wahlen durch Handaufheben erfolgen, wenn kein Abgeordneter widerspricht. Auf Antrag erfolgt dann nach der Geschäftsordnung eine schriftliche Wahl mit Stimmzetteln. Bei den beiden hier untersuchten Wahlen wurden auf Antrag der Oppositionsfraktion die Abstimmungen jeweils schriftlich, das heißt geheim durchgeführt. ${ }^{64}$

I Jörg Hopfe (Hrsg.), Die Verfassung des Freistaats Thüringen. Kommentar, Stuttgart 1994, Art. 70 Rn. 13 mit weiteren Nachweisen.

57 Vgl. PlPr. 12/01 vom 29. September 1999, S. 7 f. und PIPr. 13/01 vom 29. September 2004, S. 7.

58 Vgl. PIPr. 15/3 vom 17. Januar 2002, S. 85 - 98; PIPr. 16/3 vom 23. November 2006, S. 113 129.

59 Vgl. PlPr. 16/2 vom 4. Juli 2003, S. 25 - 34; PIPr. 16/48 vom 8. November 2005, S. 3055 3065; PIPr. 17/2 vom 29. Juni 2007, S. $19-30$.

60 Vgl. PlPr. 16/3 vom 27. Oktober 2009, S. $82-91$.

61 Vgl. PIPr. 15/2 vom 7. Oktober 2003, S. 18 f.; PlPr. 15/103 vom 9. Oktober 2007, S.7651 7657. Der letztere Beleg ist die Wahl Günther Becksteins nach dem innerparteilich erzwungenen Rücktritt von Edmund Stoiber; der erste Beleg ist die Wahl Edmund Stoibers nach seinem großen Wahlsieg.

62 In Rheinland-Pfalz findet keine der in der Verfassung geregelten Wahl geheim statt; vgl. zum Beispiel Art. 134 Abs.3 S.1 LV-RP (Wahl der Mitglieder des Verfassungsgerichtshofes) und Art. 85 Abs.2 LV-RP (Wahl des Präsidenten des Landtages und seiner Stellvertreter).

63 Vgl. $\$ 4$ S.1 in Verbindung mit $\$ 49$ Abs.1 S.1 GOBT.

64 Vgl. PlPr. 12/1 vom 29. September 1999, S. 7 f.; PIPr. 13/1 vom 29. September 2004, S. 7. 
Durch die verdeckte Wahl soll eine „unbeeinflusste, freie Entscheidung“ herbeigeführt werden. ${ }^{65}$ Diese Verfahrensvorschrift dient der Unabhängigkeit von Partei und Fraktion sowie der Verwirklichung der freien Gewissensentscheidung der Abgeordneten ${ }^{66}$, die diesen in allen Landesverfassungen ausdrücklich zugesichert wird. ${ }^{67}$ Rainer Litten sieht den Sinn dieser Vorschrift darin, „den Hinterbänklern der künftigen Regierungsfraktionen rechtzeitig Gelegenheit zum Widerstand gegen den Kandidaten zu geben“; das sichere auch die „Stabilität der künftigen Regierung"68.

Die Rechtsfolge eines Verstoßes gegen die Verfahrensregel „,in geheimer Abstimmung“ ist je nach Standort der Regelung unterschiedlich. Während in den neun Bundesländern mit verfassungsrechtlicher Absicherung der geheimen Wahl ein Verstoß unweigerlich zur Ungültigkeit der Wahl führt ${ }^{69}$, dürfte dies in den sechs Ländern, wo das Verfahren nur in der Geschäftsordnung geregelt ist, nicht der Fall sein. Nach wohl herrschender Ansicht führen nämlich Verstöße gegen die Geschäftsordnung bei parlamentarischen Beschlüssen mit Außenwirkung nicht zur Ungültigkeit oder Unwirksamkeit. ${ }^{70}$ Ein Verstoß gegen die einfachgesetzliche Regelung in Hamburg dürfte - wie bei der verfassungsrechtlichen Absicherung - ebenfalls zur Ungültigkeit der Wahl führen.

Verfassungspolitisch wäre es angebracht, das Kriterium „geheim“ in allen Bundesländern in den Landesverfassungen abzusichern, denn eine verdeckte Wahl dient gleichzeitig der Verwirklichung der freien Gewissensentscheidung der Abgeordneten, die - wie bereits erwähnt - in allen Landesverfassungen ausdrücklich zugesichert wird. ${ }^{71}$

Praxis der geheimen Abstimmung in den Landtagen

Die Wahlen in den einzelnen Bundesländern laufen üblicherweise nach folgendem „Ritual“ ab: Nach dem meist alphabetischen Namensaufruf der Abgeordneten werden die Wahlunterlagen an die Wahlberechtigten ausgegeben. Die geheime Wahl erfolgt meist in Kabinen, und mit dem Einwurf des Stimmzettels in die Wahlurne wird der Wahlvorgang abgeschlossen.

65 So Klaus Braun, a.a.O. (Fn. 53), Art. 46 Rn. 15.

66 Vgl. Hubert Weis, a.a.O. (Fn. 43), S. 27; Joachim Linck, a.a.O. (Fn. 56), Art. 70 Rn. 13; Heinzgeorg Neumann, a.a.O. (Fn. 22), Art. 29 Rn. 7; Bernd Kunzmann, in: ders. / Michael Haas / Harald Baumann-Hasske (Hrsg.), Die Verfassung des Freistaates Sachsen, Berlin 1997, Art. 60 Rn. 8.

67 Vgl. Art. 27 Abs.3 LV-BW, Art. 13 Abs.2 LV-BY, Art. 38 Abs.3 LV-B, Art. 56 Abs.1 LV-BBG, Art. 83 Abs. 1 LV-HB, Art. 7 Abs.1 LV-HH, Art. 76 / 77 LV-HE, Art. 22 Abs.1 LV-MV, Art. 12 LV-NS, Art. 30 LV-NRW, Art. 79 Abs.2 LV-RP, Art. 66 Abs.2 LV-SL, Art. 39 Abs.3 LV-S, Art. 41 Abs.2 LV-SA, Art. 11 Abs.1 LV-SH, Art. 53 Abs.1 LV-TH.

68 Rainer Litten, a.a.O. (Fn. 53), Art. 42 Rn. 4.

69 Vgl. Alfred Katz, a.a.O. (Fn. 19), Art. 46 Rn. 6; Klaus Braun, a.a.O. (Fn. 53), Art. 46 Rn. 15; Heinzgeorg Neumann, a.a.O. (Fn. 22), Art. 29 Rn. 7; Bernd Kunzmann, a.a.O. (Fn. 66), Art. 60 Rn. 8 mit weiteren Nachweisen; Andreas Reich, Verfassung des Landes Sachsen-Anhalt. Kommentar, Bad Honnef 1994, Art. 65 Rn. 1.

70 Vgl. hier die Nachweise bei Heinz-Willi Heynckes, Das Ausschussverfahren nach der Geschäftsordnung des Deutschen Bundestages, in: ZParl, 39. Jg. (2008), H. 3, S. 459 - 477, S. 459 (insbesondere Fußnote 1).

71 Zur politikwissenschaftlichen Diskussion über die offene Wahl vgl. Udo Kempf, Offene Wahl der Regierungschefs? Eine Kontroverse im neuen Jahrbuch für Politik, in: ZParl, 23. Jg. (1992), H. 2, S. 377 - 379; zur offenen Wahl vgl. Winfried Steffani, Parlamentarische Demokratie, Opladen 1979, S. 89; ders., Gewaltenteilung und Parteien im Wandel, Opladen 1997, S. 227 - 243. 


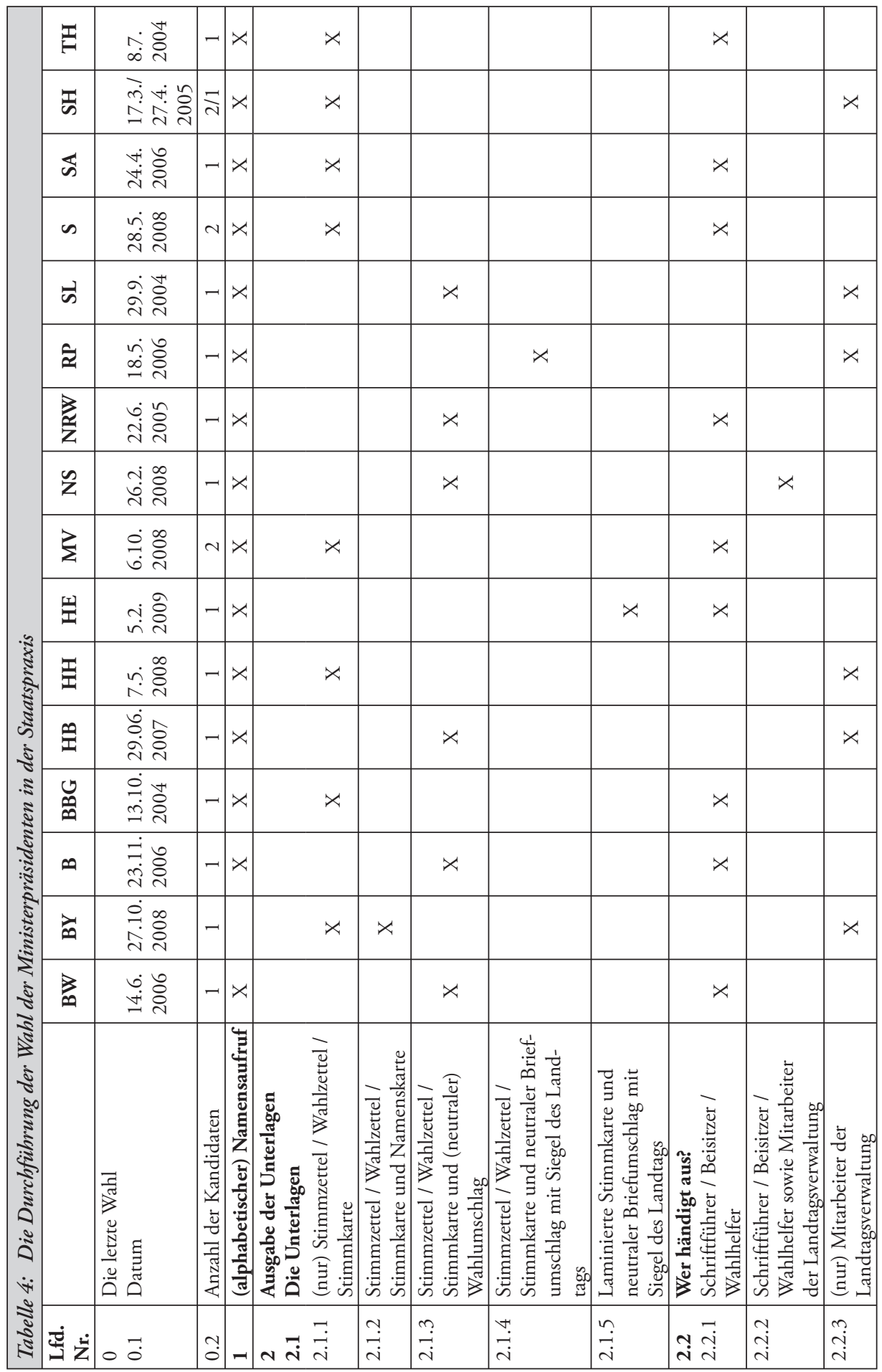




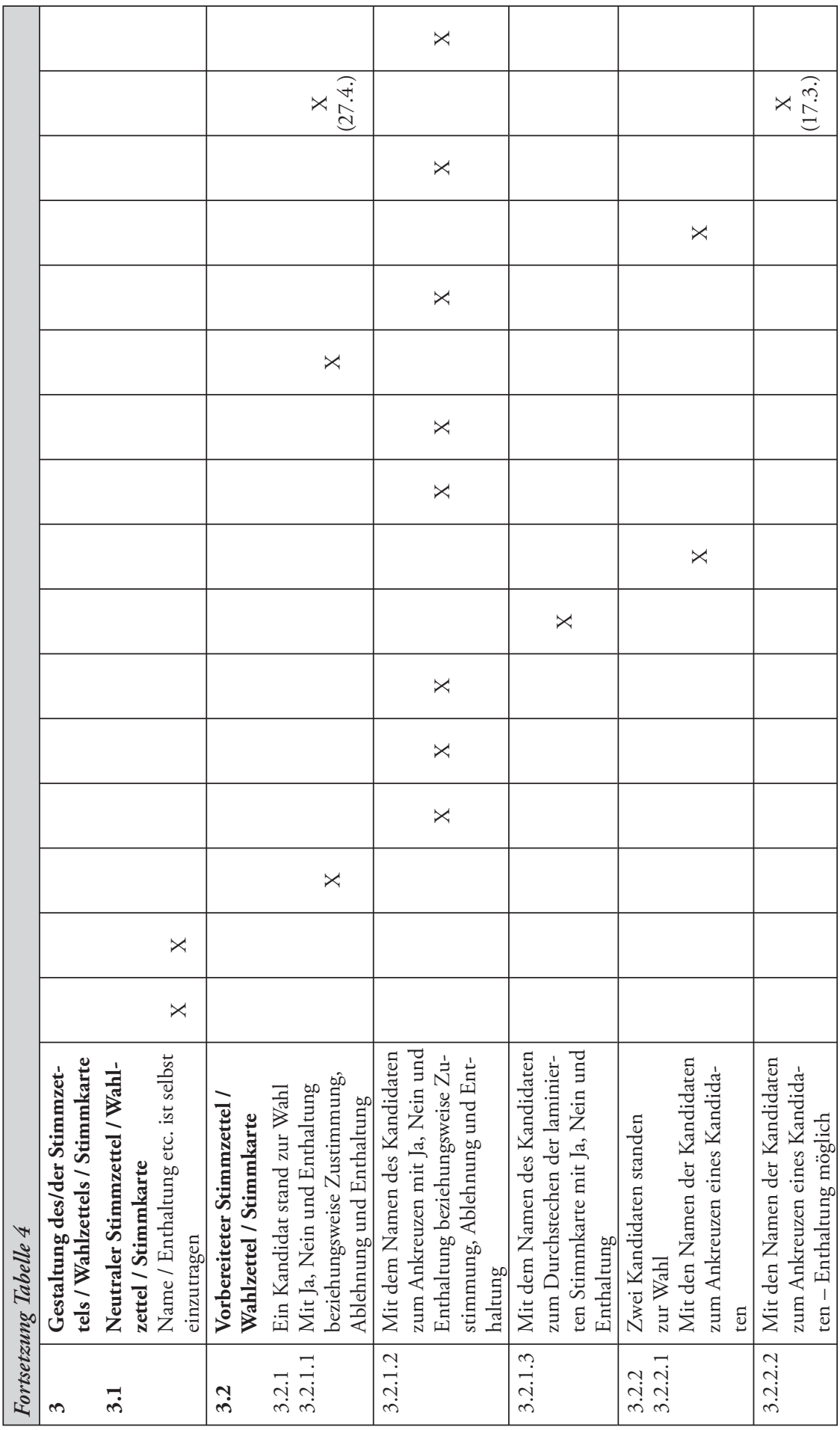




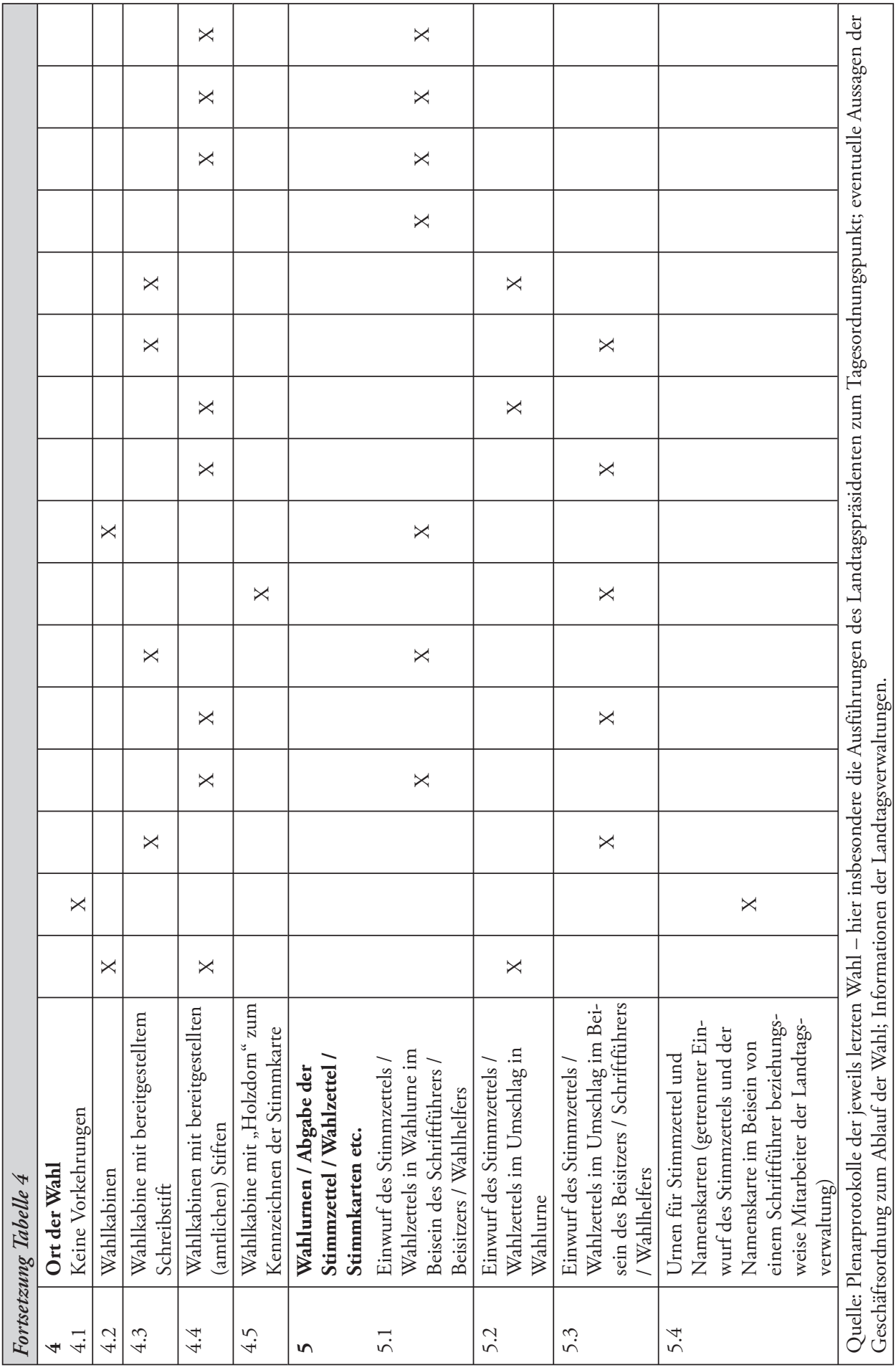


Bei diesen einzelnen Schritten sind jedoch einige nicht ganz unwesentliche Unterschiede in der Staatspraxis der Bundesländer festzustellen, die auch in unterschiedlicher Form dem Gebot der geheimen Wahl Rechnung tragen. Grundlage des folgenden Vergleichs ist die jeweils letzte Wahl des Ministerpräsidenten in den sechzehn Bundesländern (vgl. Tabelle 4). ${ }^{72}$

In allen Bundesländern außer Bayern wird die Kontrolle der an der Wahl teilnehmenden Mitglieder des Landtages durch einen namentlichen Aufruf vorgenommen. In Bayern erhalten die Abgeordneten neben ihrem Stimmzettel noch eine Namenskarte, die sie bei der Stimmabgabe in eine separate Urne einwerfen. Den Abgeordneten wird dann eine unterschiedliche Anzahl von Wahlunterlagen ausgehändigt: In acht Bundesländern erhalten die Abgeordneten nur den Stimmzettel, beziehungsweise den Wahlzettel oder die Stimmkarte. In den anderen acht gehört zu den Wahlunterlagen auch ein Umschlag für den Stimmzettel. In Hessen und Rheinland-Pfalz sind die Umschläge mit dem Siegel des Landtages versehen. Die Wahlunterlagen werden meist von den Schriftführern beziehungsweise Beisitzern und Wahlhelfern ausgeteilt, in sechs Bundesländern von Mitarbeitern der Landtagsverwaltungen.

Durch die Gestaltung des Stimmzettels ist einerseits eine unterschiedliche Transparenz des Wahlergebnisses möglich, aber andererseits kann eine bestimmte Gestaltung auch zur Verbesserung der geheimen Wahl beitragen. In Baden-Württemberg und Bayern wurden bei den Ministerpräsidentenwahlen (nur) neutrale Stimmzettel verteilt, auf denen die Abgeordneten in Baden-Württemberg den Namen des Kandidaten schreiben ${ }^{73}$ beziehungsweise in Bayern den Stimmzettel mit dem Namen oder mit "Ja“, „Nein“ oder „Enthaltung“ kennzeichnen konnten. ${ }^{74}$ In den anderen Ländern wurden bei den Wahlen vorbereitete Stimmzettel verteilt. In den zwei Bundesländern mit den neutralen, selbst auszufüllenden Stimmzetteln ist - wegen der persönlich geprägten Schriften und der verschiedenen Schreibgeräte der Angeordneten - mindestens theoretisch ein gewisser Nachvollzug von einzelnen Abstimmungen möglich. Eine solche Möglichkeit wird bei den vorbereiteten Stimmzetteln, auf denen nur angekreuzt werden muss, viel unwahrscheinlicher.

Bei den zwölf Wahlen mit nur einem Kandidaten enthielten in neun Bundesländern die vorbereiteten Stimmzettel den Namen des Kandidaten sowie die Kennzeichnungsfelder Ja, Nein und Enthaltung beziehungsweise Zustimmung, Ablehnung und Enthaltung. In Berlin, Rheinland-Pfalz und Schleswig-Holstein wiesen die Stimmzettel nur die Kennzeichnungsfelder Ja, Nein und Enthaltung beziehungsweise Zustimmung, Ablehnung und Enthaltung auf. Bei all diesen Stimmzetteln erfolgte - mit Ausnahme von Hessen - die Wahl durch Ankreuzen einer der drei Kennzeichnungsfelder.

In Sorge um die Einhaltung des Wahlgeheimnisses im Zusammenhang mit der zweimal geplanten Wahl von Andrea Ypsilanti führte der Hessische Landtag für die letzte Ministerpräsidentenwahl laminierte Stimmkarten ein. ${ }^{75}$ Auf diesen befanden sich neben dem Namen des Kandidaten auch vorgestanzte Löcher bei den Kennzeichnungsfeldern Ja, Nein und Enthaltung. Diese mussten die Abgeordneten mit einem Dorn (Holzstift) durchstechen. ${ }^{76}$

72 Der Beitrag wurde abgeschlossen vor den Wahlen in Thüringen, Sachsen, Schleswig-Holstein, Brandenburg und im Saarland (2009) sowie in Nordrhein-Westfalen (2010), so dass für diese Länder jeweils die vorletzte Wahl berücksichtigt wurde.

73 Vgl. PlPr. 14/2 vom 14. Juni 2006, S. 29.

74 Vgl. PIPr. 16/3 vom 27. Oktober 2008, S. 92.

75 Vgl. Besondere Stimmzettel für Wahl Ypsilantis, in: FAZ vom 29. Oktober 2008, S. 1; Georg Paul Hefty, Freiheitsgarant, in: FAZ vom 4. November 2008, S. 10.

76 Hinweise des Landtagspräsidenten, vgl. PIPr. 18/1 vom 5. Februar 2009, S. 15. 
Bei den drei Wahlen mit zwei Kandidaten waren auf den Stimmzetteln in MecklenburgVorpommern und Sachsen nur die Namen der zwei Kandidaten verzeichnet, während bei der nicht erfolgreichen Wahl in Schleswig-Holstein am 17. März 2005 der Stimmzettel neben den beiden Namen auch ein Kennzeichnungsfeld Enthaltung hatte. In Mecklenburg-Vorpommern und Sachsen wurden jedoch nicht gekennzeichnete Stimmzettel als Stimmenthaltungen gewertet (vgl. Tabelle 1).

Außer in Bayern musste in allen Bundesländern der Stimmzettel in einer Wahlkabine gekennzeichnet werden. Dort wurden meist auch Schreibgeräte bereitgestellt. In acht Bundesländern durfte die Stimmabgabe nur mit einem amtlichen Stift vorgenommen werden.

Die ausgefüllten Wahlunterlagen waren sodann in die vorgesehenen Urnen zu werfen. Der Einwurf der Stimmzettel - eventuell im entsprechenden Umschlag - erfolgte meist im Beisein des Schriftführers oder Beisitzers / Wahlhelfers beziehungsweise der Mitarbeiter des Landtages.

\section{Erforderliche Mehrheiten}

\subsection{Bundesländer mit erforderlicher Mitgliedermehrheit}

In allen Bundesländern mit Ausnahme von Bayern, Berlin und Bremen ist für eine erfolgreiche Wahl des Ministerpräsidenten im ersten Wahlgang die Mehrheit der Mitglieder des Landtags erforderlich. Mit dieser verfassungsrechtlich abgesicherten absoluten Mehrheit wird einerseits die Wahl des Regierungschefs hervorgehoben ${ }^{77}$; andererseits soll diese qualifizierte Mehrheit Zufallsergebnisse ausschließen und die Wahl eines Minderheitsministerpräsidenten verhindern. ${ }^{78}$ Wegen der fortdauernden Abhängigkeit des Regierungschefs vom Vertrauen des Landesparlaments kann eine solche mit qualifizierter Mehrheit erfolgte Wahl auch den notwendigen politischen Rückhalt für den Beginn der Regierungstätigkeit geben. ${ }^{79}$

Bei der Berechnung der Mehrheit ist entscheidend, ob in dem entsprechenden Bundesland Überhang- und/oder Ausgleichsmandate möglich sind. So beträgt die Zahl der Mitglieder des Saarländischen Landtags nach Art. 77 Abs. 1 Satz 1 und 66 Abs.1 LV-SL exakt 51 Mitglieder. Da in diesem Bundesland keine Überhang- und Ausgleichsmandate möglich sind, ist nur der Kandidat gewählt, für den 26 Abgeordnete stimmen. Nicht abgegebene oder ungültige Stimmen sowie Enthaltungen wirken sich bei diesem Wahlgang wie NeinStimmen aus. ${ }^{80}$

In den meisten Fällen müssen jedoch für die Berechnung der exakten Zahl der Mitglieder der jeweiligen Landtage neben der verfassungsrechtlichen Grundregelung noch die entsprechenden Bestimmungen der Landeswahlgesetze herangezogen werden, wenn wegen Über-

77 Vgl. Peter J. Tettinger, a.a.O. (Fn. 20), Art. 52 Rn. 27; Heinzgeorg Neumann, a.a.O. (Fn. 22), Art. 29 Rn. 8.

78 Vgl. Alfred Katz, a.a.O. (Fn. 19), Art. 46 Rn. 6; Klaus Braun, a.a.O. (Fn. 53), Art. 46 Rn. 2; Klaus David, Verfassung der Freien und Hansestadt Hamburg. Kommentar, Stuttgart 2004, Art. 34 Rn. 14; Rolf Groß, a.a.O. (Fn. 43), Art. 101 Rn. 7.

$79 \mathrm{Vgl}$. Adolf Süsterhenn / Hans Schäfer, Kommentar der Verfassung für Rheinland-Pfalz, Koblenz 1950, Art. 98 Anm. 3.

80 Vgl. statt vieler Klaus-Eckart Gebauer, a.a.O. (Fn. 18), Art. 98 Rn. 14. 
hang- und/oder Ausgleichsmandaten die Mehrheit in den Wahlperioden variieren kann. So bestand der Hessische Landtag in der 16. und 17. Wahlperiode aus 110, in der 18. Wahlperiode aus 118 Abgeordneten. Dies führte dazu, dass bei den anstehenden Wahlen in den letzten Wahlperioden unterschiedliche Stimmenzahlen erforderlich waren (vgl. Tabelle 1).

\subsection{Bundesländer mit erforderlicher Abstimmungsmehrheit}

Wie bereits erwähnt ist in Bayern sowie in den Stadtstaaten Berlin und Bremen für die Wahl des Regierungschefs nur die Mehrheit der abgegebenen Stimmen erforderlich. ${ }^{81}$ Die so genannte einfache Mehrheit ist dann erreicht, wenn der Kandidat mindestens eine JaStimme mehr als Nein-Stimmen hat. Nach der herrschenden Literaturmeinung werden dabei Stimmenthaltungen und ungültige Stimmen nicht berücksichtigt. ${ }^{82}$ Wohl könnte man sprachlich gesehen Enthaltungen noch als abgegebene Stimmen ansehen, jedoch entspricht dies nicht der historischen Auslegung. ${ }^{83}$

Diese Ansicht wird nicht in Berlin praktiziert, weil nach $₫ 75$ Abs.1 S.3 GO-Abgeordnetenhaus-B für die Wahl des Regierenden Bürgermeisters festgelegt ist, dass Enthaltungen und ungültige Stimmen bei der Ermittlung der Mehrheit der abgegebenen Stimmen mitzuzählen sind, das heißt diese beiden Abstimmungsverhalten werden wie Nein-Stimmen behandelt. Dies bedeutet eigentlich, dass es sich hier um eine Qualifizierung der so genannten einfachen Mehrheit handelt. Diese verfassungsrechtlich und verfassungspolitisch problematische Ausnahmeregelung ${ }^{84}$ führte bei der Wahl des Regierenden Bürgermeisters in der 16. Wahlperiode dazu, dass ein zweiter Wahlgang notwendig wurde. ${ }^{85}$ Im ersten Wahlgang erhielt Klaus Wowereit 74 Stimmen. Mit „Nein“ stimmten 73 Abgeordnete, zwei enthielten sich. Da diese Voten wie Nein-Stimmen zu zählen waren, hatte der Kandidat nicht die erforderliche Mehrheit. ${ }^{86}$

Damit ein Regierungschef in diesen drei Bundesländern nicht mit „Kleinstmehrheiten“ ins Amt gelangt, sind die entsprechenden Regelungen über die Beschlussfähigkeit zu beachten. ${ }^{87}$ Danach muss für einen gültigen Beschluss mindestens die Mehrheit der Mitglieder

81 Vgl. die gesetzlichen Fundstellen in Tabelle 3 Spalte 4 sowie in Tabelle 1 Spalte 6.

82 Vgl. hierzu die ausführliche Darstellung und die Hinweise auf die Mindermeinung bei Manfred J. Neumann, a.a.O. (Fn. 40), Art. 56 Rn. 7; sowie für die Rechtslage im Bund Hans H. Klein, in: Theodor Maunz / Günter Dürig (Hrsg.), Grundgesetz. Kommentar, Loseblattsammlung, München 2008, Art. 42 Rn. 84. Die Mindermeinung wird dargestellt bei Hans-Joachim Driehaus (Hrsg.), Verfassung für Berlin. Taschenkommentar, Baden-Baden 2002, Art. 56 Rn. 3; vgl. die Darstellungen zu den entsprechenden Ländern bei Karl Schweiger, a.a.O. (Fn. 23), Art. 23 Rn. 3; Manfred J. Neumann, a.a.O. (Fn. 40), Art. 56 Rn. 7; Heinzgeorg Neumann, Die Verfassung der Freien Hansestadt Bremen. Kommentar, Stuttgart 1996, Art. 90 Rn. 6 ff.

83 Vgl. Hans H. Klein, a.a.O. (Fn. 82), Art. 42 Rn. 84.

84 Vgl. dazu Manfred J. Neumann, a.a.O. (Fn. 40), Art. 56 Rn. 8 mit weiteren Nachweisen.

85 Vgl. Zeile 3.2 der Tabelle 1.

86 Diese etwas „schwierigere” Rechnung - Einbeziehung der Enthaltungen als Nein-Stimmen führte selbst bei einem so erfahrenen amtierenden Parlamentspräsidenten wie Walter Momper dazu, dass er schon bei diesem Ergebnis zur Vereidigung aufforderte und erst nach Zuruf und Belehrung feststelle, dass die erforderliche Mehrheit nicht erreicht sei; vgl. PIPr. 16/3 vom 23. November 2006, S. 130.

87 Vgl. Art. 23 Abs.2 LV-BY; Art. 43 LV-B; Art. 89 LV-HB. 
anwesend sein. Das bedeutet jedoch, dass theoretisch eine kleine Anzahl von Abgeordneten, nämlich die Zustimmung eines Viertels der Mitglieder, ausreichend ist. ${ }^{88}$

\subsection{Rechtsfolgen, wenn kein Kandidat im ersten Wahlgang die erforderliche Mehrheit erreicht}

In den drei Bundesländern (Bayern, Berlin und Bremen), in denen nur die einfache Mehrheit für die Wahl erforderlich ist, können nach einem erfolglosen Wahlgang weitere folgen. In Bayern ist jedoch der Zeitraum für die weiteren Wahlgänge auf vier Wochen beschränkt. ${ }^{89}$ Falls es zu keiner Regierungsbildung kommt, können sich die Landtage in diesen Ländern selbst auflösen. ${ }^{90}$

Von den dreizehn Bundesländern mit erforderlicher absoluter Mehrheit muss in fünf (Baden-Württemberg, Hamburg, Hessen, Rheinland-Pfalz und dem Saarland) auch für die folgenden Wahlgänge die Mehrheit der gesetzlichen Mitglieder erreicht werden. ${ }^{91}$ In Baden-Württemberg und im Saarland ist der Zeitraum für weitere Wahlmöglichkeiten beziehungsweise die Regierungsbildung auf drei Monate beschränkt; ansonsten ist der Landtag aufgelöst. ${ }^{92}$ Wiederholungen der Wahl beziehungsweise beliebig viele Abstimmungen sind innerhalb des von der Verfassung vorgeschriebenen Zeitraums möglich. ${ }^{93}$ Die Drohung mit der Landtagsauflösung kraft Verfassung gibt es in den anderen drei Bundesländern (Hamburg, Hessen und Rheinland-Pfalz) nicht; auch dort kann solange gewählt werden, bis ein Kandidat die erforderliche Mehrheit erreicht hat. ${ }^{94}$ Jedoch besteht in diesen Bundesländern ein Selbstauflösungsrecht des Landtages. ${ }^{95}$ Davon machte der Hessische Landtag in der 17. Wahlperiode Gebrauch, nachdem keine Ministerpräsidentenwahl zustande kam. Dadurch wurde bereits nach nur einem Jahr ein neuer Landtag gewählt. ${ }^{96}$

Teilweise vielschichtigere Lösungen gibt es in den acht anderen Bundesländern, die für den ersten Wahlgang die absolute Mehrheit fordern. ${ }^{97}$ An deren Ende steht entweder ein gewählter „Minderheits-Ministerpräsident“ oder die Auflösung des Landtages.

- Die Verfassungen von Brandenburg, Schleswig-Holstein und Thüringen fordern für den ersten und zweiten Wahlgang die Mehrheit der Mitglieder, in einem möglichen dritten Wahlgang ist die Mehrheit der abgegebenen Stimmen ausreichend. Nach wohl richtiger Ansicht ${ }^{98}$ dürfen im Rahmen dieses dritten Wahlganges mehrere Abstimmungen durchgeführt werden - gleichsam solange, bis der Landtag sich selbst auflöst. ${ }^{99}$ So wurden bei der letzten Ministerpräsidentenwahl in Schleswig-Holstein im Jahre 2005

88 Hans-Joachim Driehaus, a.a.O. (Fn. 82), Art. 56 Rn. 2 hält dieses geringe Mindestquorum für ungewöhnlich.

89 Vgl. die Fundstelle der entsprechenden Regelung in Tabelle 2 Spalte 3.

90 Vgl. Art. 18 LV-BY; Art. 54 Abs.2 LV-B; Art. 76 LV-HB.

91 Vgl. die Fundstellen der entsprechenden Regelungen in Tabelle 2 Spalte 3.

92 Vgl. die Fundstellen der entsprechenden Regelungen in Tabelle 2 Spalte 3.

93 Vgl. Klaus Braun, (Fn. 53), Art. 46 Rn. 18.

94 Vgl. Rolf Groß, a.a.O. (Fn. 43), Art. 101 Rn. 7.

95 Vgl. Art. 11 LV-HH; Art. 80 LV-HE; Art. 84 LV-RP.

96 Vgl. hierzu Rüdiger Schmitt-Beck / Thorsten Faas, Die hessische Landtagswahl vom 27. Januar 2008: Wiederkehr der „hessischen Verhältnisse“, in: ZParl, 40. Jg. (2009), H. 1, S. $16-34$.

97 Vgl. die entsprechenden Regelungen in Tabelle 2 Spalte 3.

98 Vgl. Martin Nolte, a.a.O. (Fn. 21), Art. 26 Rn. 15; Joachim Linck, a.a.O. (Fn. 56), Art. 70 Rn. 14.

99 Vgl. Joachim Linck, a.a.O. (Fn. 56), Art.70 Rn.14. 
im Rahmen des dritten Wahlganges an zwei Tagen drei Abstimmungen durchgeführt, an deren Ende ein neuer Ministerpräsident stand, der dann sogar mehr als die geforderte einfache Mehrheit erhalten hatte (vgl. Tabelle 1). ${ }^{100}$

- In Sachsen ist schon im zweiten Wahlgang die einfache Mehrheit ausreichend. Falls jedoch innerhalb von vier Monaten kein neuer Ministerpräsident gewählt wird, ist der Landtag kraft Verfassung aufgelöst. ${ }^{101}$ Bei der zweiten Wahl von Georg Milbradt am 10. November 2004 waren die schon im ersten Wahlgang erzielten 62 Ja-Stimmen als Abstimmungsmehrheit ausreichend (vgl. Tabelle 1). Die Fristenregelung spricht dafür, dass im zweiten Wahlgang - wie in Brandenburg, Schleswig-Holstein und Thüringen - mehrere Abstimmungen durchgeführt werden können. ${ }^{102}$

- Die Verfassung von Nordrhein-Westfalen reduziert bereits für den zweiten und dritten Wahlgang die Mehrheit auf die Mehrheit der abgegebenen Stimmen. Diese beiden Wahlgänge müssen jedoch innerhalb von 14 Tagen erfolgen. ${ }^{103}$ Auch hier dürfte gelten, dass innerhalb des Zeitrahmens mehrere Abstimmungen erfolgen können. Die Sinnhaftigkeit der zwingenden Fristsetzung ist aber in Ermangelung des Drohpotentials einer Landtagsauflösung fraglich. ${ }^{104}$ Jedoch ist nach Art. 35 LV-NRW eine Selbstauflösung des Landtages möglich. Erreicht in diesen beiden Wahlgängen kein Kandidat die notwendige relative Mehrheit, so ist - gleichsam in einem vierten Wahlgang - nach Art. 52 Abs.2 S.2 LV-NRW eine Stichwahl zwischen den beiden Kandidaten mit den meisten Stimmen durchzuführen. ${ }^{105}$

- Die Verfassungen von Mecklenburg-Vorpommern und Niedersachsen haben Regelungen, an deren Ende entweder die Landtagsauflösung oder die Wahl eines Minderheitsregierungschefs steht. ${ }^{106}$ Nach „diesem äußerst komplizierten Verfahren “107 muss der Landtag, wenn innerhalb einer bestimmten Frist keine Ministerpräsidentenwahl mit der absoluten Mehrheit beziehungsweise eine Regierung zustande kommt - wieder innerhalb einer bestimmten Frist -, über seine Aufösung entscheiden. Geschieht dies, findet ein neuer Wahlgang statt, in dem derjenige gewählt ist, der die meisten Stimmen erhält. $\mathrm{Ob}$ hier weitere Abstimmungen, die rechtlich möglich sein dürften, tatsächlich durchgeführt werden können, scheint bei den geforderten kurzen Fristen Mecklenburg-Vorpommern: Wahl am selben Tag; Niedersachsen: Wahl unverzüglich - zweifelhaft, zumindest aber sehr schwierig. ${ }^{108}$

- $\quad$ Ähnlich ist auch die Regelung in Sachsen-Anhalt. ${ }^{109}$ Hier erfolgt der Beschluss über die Landtagsauflösung erst nach zwei erfolglosen - innerhalb einer Frist von sieben

100 Am Anfang der Wahl am 27. April 2005 wies der Landtagspräsident daraufhin, dass gemäß Art. 26 Abs.4 S.2 LV-SH abgestimmt werde. Dies ist die Bestimmung über die einfache Mehrheit im dritten Wahlgang.

101 Vgl. die Fundstelle der entsprechenden Regelung in Tabelle 2 Spalte 3.

102 Vgl. dazu mit Hinweis auf den Willen des Verfassungsgebers Bernd Kunzmann, a.a.O. (Fn. 66), Art. 60 Rn. 11.

103 Vgl. die Fundstelle der entsprechenden Regelung in Tabelle 2 Spalte 3.

104 Vgl. Peter J. Tettinger, a.a.O. (Fn. 20), Art. 52 Rn. 29.

$105 \mathrm{Zu}$ dieser problematischen Regelung vgl. ebenda, Art. 52 Rn. 34 ff.

106 Vgl. die Fundstellen sowie die Details der entsprechenden Regelungen in Tabelle 2 Spalte 3.

107 So Hans-Peter Schneider zitiert in: Heinzgeorg Neumann, a.a.O. (Fn. 22), Art. 29 Rn. 2.

108 Vgl. Rainer Litten, a.a.O. (Fn. 53), Art. 42 Rn. 10. Hier wird auch kurz die Problematik der Patt-Situation angesprochen.

109 Vgl. die Fundstelle sowie die Details der entsprechenden Regelung in Tabelle 2 Spalte 3. 
Tagen durchzuführenden - Wahlgängen, bei denen die Mehrheit der Mitglieder gefordert wird. Wird dann innerhalb von vierzehn Tagen die Auflösung nicht beschlossen, findet unverzüglich ein neuer Wahlgang statt, auf dem dann auch derjenige zum Ministerpräsidenten gewählt ist, der die meisten Stimmen erhält. Auch hier dürften beliebig viele Abstimmungen möglich sein. ${ }^{110}$

\subsection{Die Wahlergebnisse in der derzeitigen und vorangegangenen Wahlperiode}

In den beiden letzten Wahlperioden haben mit einer Ausnahme bei allen Ministerpräsidentenwahlen die gewählten Kandidaten die Mehrheit der Mitglieder des jeweiligen Landtags erhalten (vgl. Tabelle 1). Drei Besonderheiten sollen hier hervorgehoben werden:

(1) Der sächsische Ministerpräsident Georg Milbradt kam am 10. November 2004 erst im zweiten Wahlgang mit der dann geforderten einfachen Mehrheit, der Mehrheit der Stimmen, in sein Amt.

(2) Auch Klaus Wowereit erreichte bei seiner Wahl am 23. November 2006 im Berliner Abgeordnetenhaus erst im zweiten Wahlgang die erforderliche Mehrheit der abgegebenen Stimmen. ${ }^{111}$

(3) Die Wahl von Peter Harry Carstensen zum Ministerpräsidenten von Schleswig-Holstein am 27. April 2005 erfolgte erst nach vier erfolglosen Abstimmungen am 17. Februar 2005 - jedoch mit der absoluten Mehrheit und nicht der für diesen Wahlgang geforderten einfachen Mehrheit.

Interessante Aufschlüsse gibt die Auswertung der Wahlergebnisse hinsichtlich der Differenz zwischen der erreichten Stimmenzahl und der Anzahl der Mitglieder der Fraktionen, die die Regierung tragen (vgl. Tabelle 5 und Tabelle 1).

(1) Bei zehn der 44 Wahlgänge (22,7 Prozent) erhielt der gewählte Kandidat alle Stimmen der Regierungskoalition und bei sieben Wahlen (15,9 Prozent) sogar mehr Stimmen, als die Regierungsfraktionen über Sitze verfügten.

(2) Dagegen erhielten die gewählten Kandidaten bei 27 Wahlen (61,4 Prozent) nicht alle Stimmen der Regierungskoalition. Bei vier Wahlen (9,1 Prozent) war die negative Abweichung größer als zehn Prozent der Stimmen. Dabei handelte es sich nur um Ministerpräsidentenwahlen bei so genannten Großen Koalitionen.

(3) In sechs Bundesländern ${ }^{112}$ gibt beziehungsweise gab es Große Koalitionen aus Union und Sozialdemokraten. Bei den dort durchgeführten elf Wahlen wurde nie die Gesamtstimmenzahl der Regierungskoalitionen erreicht. Die negativen Abweichungen waren hier besonders groß, und zwar betrug die Differenz bei fünf Wahlen fünf bis zehn Prozent $(45,5$ Prozent) und bei vier Wahlen sogar mehr als zehn Prozent (36,5 Prozent). Diese beträchtliche Abweichung vom Durchschnitt ist sicher einerseits Ausdruck der meist ungeliebten

110 Vgl. Andreas Reich, a.a.O. (Fn. 69), Art. 66 Rn. 6.

111 Zur Problematik der Berücksichtigung der ungültigen Stimmen und der Stimmenthaltungen nach $₫ 75$ Abs.1 S.3 GO-Abgeordnetenhaus-B vgl. die Ausführungen im vorangegangenen Abschnitt.

112 Vgl. die entsprechenden Angaben zu Brandenburg, Bremen, Mecklenburg-Vorpommern, Sachsen, Sachsen-Anhalt und Schleswig-Holstein in Tabelle 1; die Koalition in Sachsen wurde hier mit einbezogen, obwohl die SPD dort nicht die zweitgrößte Fraktion im Landtag stellt. 


\begin{tabular}{|c|c|c|c|}
\hline \multicolumn{4}{|c|}{$\begin{aligned} \text { Tabelle 5: } & \text { Ergebnisse der Wablen der Ministerpräsidenten in der derzeitigen und vorangegangenen } \\
& \text { Wahlperiode (Differenzen zur Anzabl der Mitglieder der Regierungskoalition) }\end{aligned}$} \\
\hline $\begin{array}{l}\text { Lfd. } \\
\text { Nr. }\end{array}$ & Kategorien & $\begin{array}{c}\text { Wahlen } \\
\text { Bundesland - Wahlgang gemäß Tabelle } 1\end{array}$ & $\begin{array}{c}\text { Anzahl der } \\
\text { Wahl- } \\
\text { gänge / } \\
\text { Prozent }\end{array}$ \\
\hline 1 & $\begin{array}{l}\text { Mehr Stimmen als die Anzahl } \\
\text { der Regierungskoalition }\end{array}$ & $\begin{array}{l}\mathrm{BW}-1.1 .2+1.2 ; \mathrm{HH}-6.2 ; \mathrm{NRW}-10.1 .2 ; \mathrm{RP} \\
-11.2 ; \mathrm{SA}-14.1 ; \mathrm{SH}-15.1\end{array}$ & $\begin{array}{r}7 \\
15.9 \%\end{array}$ \\
\hline 2 & $\begin{array}{l}\text { Stimmen entsprechend } \\
\text { der Anzahl der Regierungs- } \\
\text { koalition }\end{array}$ & $\begin{array}{l}\mathrm{BY}-2.1 .1 ; \mathrm{HB}-5.2 ; \mathrm{HE}-7.1 ; \mathrm{MV}-8.1 ; \mathrm{NS}- \\
9.2 ; \mathrm{NRW}-10.1 .1 ; \mathrm{SL}-12.1+12.2 ; \mathrm{TH}- \\
16.1 .1+16.2\end{array}$ & $\begin{array}{r}10 \\
22,7 \%\end{array}$ \\
\hline 3 & $\begin{array}{l}\text { Bis } 5 \text { Prozent weniger } \\
\text { Stimmen als die der } \\
\text { Regierungskoalition }\end{array}$ & $\begin{array}{l}\text { BW - 1.1.1; BY - 2.1.2 + 2.2; B }-3.1+3.2(\text { zwei } \\
\text { Wahlgänge); HB - 5.1.1; HH - 6.1; NS - 9.1; } \\
\text { NRW - 10.2; RP - 11.1; } \mathrm{S}-13.1 .1+13.2 .2 ; \mathrm{SH} \\
-15.2 \text { (1. Wahlgang); TH }-16.1 .2\end{array}$ & $\begin{array}{r}15 \\
34,1 \%\end{array}$ \\
\hline 4 & $\begin{array}{l}5 \text { bis } 10 \text { Prozent weniger } \\
\text { Stimmen als die der } \\
\text { Regierungskoalition }\end{array}$ & $\begin{array}{l}\mathrm{BBG}-4.1 .1 ; \mathrm{HE}-7.3 ; \mathrm{MV}-8.2 .1 ; \mathrm{S}-13.1 .2+ \\
\text { 13.2.1 (zwei Wahlgänge); } \mathrm{SA}-14.2 ; \mathrm{SH}-15.2(2 . \\
\text { Wahlgang) }\end{array}$ & $\begin{array}{r}8 \\
18,2 \%\end{array}$ \\
\hline 5 & $\begin{array}{l}\text { Mehr als } 10 \text { Prozent weniger } \\
\text { Stimmen als die der } \\
\text { Regierungskoalition }\end{array}$ & $\mathrm{BBG}-4.1 .2+4.2 ; \mathrm{HB}-5.1 .2 ; \mathrm{MV}-8.2 .2$ & $\begin{array}{r}4 \\
9,1 \%\end{array}$ \\
\hline \multicolumn{4}{|c|}{$\begin{array}{l}\text { Anmerkungen: Es wird von insgesamt } 44 \text { Wahlgängen bei } 41 \text { Wahlen ausgegangen, da bei Wahlen in } \\
\text { Berlin (Zeile } 3.2 \text { der Tabelle } 1 \text { ) und Sachsen (Zeile 13.2.1 der Tabelle 1) zwei Wahlgänge erforderlich } \\
\text { waren. Bezüglich der Wahlen in Schleswig-Holstein wurden die Abstimmungen am 17. März } 2005 \text { und } \\
\text { der Wahlgang am 27. April } 2005 \text { wegen der Vergleichbarkeit ebenfalls als zwei Wahlgänge eingeordnet } \\
\text { (Zeile 15.2 der Tabelle 1). } \\
\text { Quelle: Eigene Auswertungen. Vgl. auch Tabelle 1. }\end{array}$} \\
\hline
\end{tabular}

Koalition; andererseits besteht aber bei einer solch großen Mehrheit leichter die Möglichkeit, einmal einen innerparteilichen Denkzettel zu verpassen.

(4) Alleinregierungen der CDU oder CSU gab es im untersuchten Zeitraum in sechs Bundesländern. ${ }^{113}$ Bei den ebenfalls elf Wahlen sind ganz andere Ergebnisse zu verzeichnen als bei der Konstellation der Großen Koalition. In mehr als der Hälfte aller Wahlen (sechs; 54,5 Prozent) erhielt der Kandidat alle Stimmen der Regierungsfraktion, und bei nur einer einzigen Wahl war die negative Differenz größer als fünf Prozent (9,1 Prozent). Bei vier Wahlen (36,3 Prozent) ist eine negative Differenz zwischen 1,3 bis 4,1 Prozent zu verzeichnen. Für die weitgehende Geschlossenheit sprechen verschiedenste Gründe. Bei den beiden Wahlen im Saarland ist es sicher ohne Zweifel die geringst mögliche Mehrheit von einer Stimme gewesen. Bei der Wahl von Edmund Stoiber am 7. Oktober 2003 gab die Freude über den haushohen Sieg der CSU sicher den Ausschlag. Auffallend ist, dass bei Wechsel des Regierungschefs innerhalb der Wahlperiode die neuen Kandidaten ein schlechteres Ergebnis erzielten als ihre Vorgänger. ${ }^{114}$ Das lag unter anderem an den vorangegangenen innerparteilichen Auseinandersetzungen über den Zeitpunkt der Nachfolge.

113 In Bayern, Hamburg, Hessen, Sachsen, Thüringen und im Saarland, vgl. Tabelle 1.

114 Vgl. Tabelle 1: Wahl von Günther Beckstein nach dem erzwungen Rücktritt von Edmund Stoiber; Wahl von Georg Milbradt nach den innerparteilichen Diskussionen über den Zeitpunkt des Rücktritts von Kurt Biedenkopf; Wahl von Dieter Althaus nach dem wohl geplanten Rückzug von Bernhard Vogel. 
(5) Merkliche positive Abweichungen vom Durchschnitt können für die neun Ministerpräsidentenwahlen bei Koalitionen der Unionsparteien mit den Liberalen festgestellt werden (vgl. Tabelle 1). Bei drei Wahlen (33,3 Prozent) erhielt der Kandidat jeweils mehr Stimmen als die Zahl der Mitglieder der Regierungsfraktion ${ }^{115}$ und bei einer Wahl (11,1 Prozent) alle Stimmen der Regierungsfraktion. Bei den anderen fünf Wahlen (55,5 Prozent) ist ein negatives Ergebnis zu verzeichnen. Eine hohe negative Differenz (minus 6,1 Prozent) gab es nur bei der letzten Wahl von Roland Koch.

(6) Noch positivere Abweichungen vom Durchschnitt sind hinsichtlich der Koalitionen zwischen SPD beziehungsweise CDU und den Grünen zu verzeichnen. ${ }^{116}$ Bei keiner dieser fünf Wahlen erhielt ein Kandidat ein negatives Ergebnis. Bei zwei Wahlen (40 Prozent) erhielt der Kandidat alle Stimmen der Regierungsparteien, und bei drei Wahlen (50 Prozent) lag die Höhe des Abstimmungsergebnisses über der Anzahl der Mitglieder der Regierungsfraktionen.

(7) Die Anzahl der Wahlen von Ministerpräsidenten durch Koalitionen von SPD und PDS beziehungsweise der Linken ist mit drei Wahlen klein. ${ }^{117}$ Hier erreichte Harald Ringstorff(Mecklenburg-Vorpommern) alle und Klaus Wowereit (Berlin) nicht alle Stimmen der beiden Regierungskoalitionen.

\section{Wablen der Ministerpräsidenten: Homogenität und Vielfalt}

Der Vergleich der Regelungen zu den Wahlen der Ministerpräsidenten im deutschen Bundesstaat zeigt einerseits eine gewisse Homogenität, andererseits aber auch deutliche Unterschiede. Beispielhaft für die „bunte“ Regelungsvielfalt sind die Lösungswege für den Fall, dass ein Kandidat im ersten Wahlgang nicht die erforderliche Mehrheit erhält. Die wenigen Vorschriften über die persönlichen Anforderungen an den zu Wählenden zeigen darüber hinaus sogar gewisse regionale Besonderheiten.

In puncto Verfahren konnte festgestellt werden, dass es teilweise große Übereinstimmungen - jedoch keine Uniformität - in den landesrechtlichen Regelungen gibt. Wie in Art. 63 Abs.1 GG für den Bundeskanzler, so wird in zwölf von sechzehn Bundesländern gefordert, dass der Regierungschef „ohne Aussprache“, und in dreizehn, dass er mit absoluter Mehrheit gewählt werden muss. Hinsichtlich des Kriteriums „in geheimer Abstimmung" ist - bei unterschiedlichem Standort der Regelungen - die Homogenität noch größer, denn nur im Saarland ist dies nicht bindend vorgeschrieben.

In den Untersuchungen zur Staatspraxis dürften die Ergebnisse der Umfrage zu den Modalitäten der geheimen Abstimmung nützlich sein, wenn es gilt, die eine oder andere Problematik neu zu regeln. Teils bekannt, aber teils auch überraschend waren die Auswertungen der Wahlergebnisse im Hinblick auf die zustande gekommenen Mehrheiten in den verschiedenen Koalitionsvarianten. Insgesamt stellt die Variationsbreite der Konfliktbewältigung eine große Materialsammlung für mögliche Verfassungsänderungen dar.

115 Zweimal in Baden-Württemberg, einmal in Sachsen-Anhalt.

116 In Bremen, Hamburg, Nordrhein-Westfalen und Schleswig-Holstein, vgl. Tabelle 1.

117 In Berlin und Mecklenburg-Vorpommern, vgl. Tabelle 1. 